\title{
Uncertainties in climate change scenarios for the Czech Republic
}

\author{
Martin Dubrovsky ${ }^{1, *}$, Ivana Nemesova ${ }^{2}$, Jaroslava Kalvova ${ }^{3}$ \\ ${ }^{1}$ Institute of Atmospheric Physics ASCR, Husova 456, 50008 Hradec Kralove, Czech Republic \\ ${ }^{2}$ Institute of Atmospheric Physics ASCR, Bocní II, 14131 Praha 4, Czech Republic \\ ${ }^{3}$ KMOP, Faculty of Mathematics and Physics, Charles University, V Holesovickach 2, 18000 Praha 8, Czech Republic
}

\begin{abstract}
Monthly series from 7 Global Climate Models (GCMs) were used to estimate forthcoming changes in global solar radiation, precipitation amount, daily average temperature, and daily temperature range in the Czech region. Scenarios were constructed using the pattern scaling technique: the standardised scenario, which relates the climate variable responses to a $1{ }^{\circ} \mathrm{C}$ rise in global mean temperature $\left(T_{\mathrm{G}}\right)$, was multiplied by the predicted change $\left(\Delta T_{\mathrm{G}}\right)$. The standardised scenarios were determined from the GCM runs, $\Delta T_{\mathrm{G}}$ values were calculated by the simple climate model MAGICC. Two groups of uncertainties were analysed: (1) uncertainties in the standardised scenario, with (1a) inter-GCM variability, (1b) internal GCM variability, (1c) uncertainty due to the choice of the site (within the Czech territory), (1d) uncertainty involved in the regression technique; (2) uncertainties in $\Delta T_{\mathrm{G}}$, with (2a) choice of the emission scenario, (2b) value of the climate sensitivity factor. In the case of Group 1, (1a) dominated, (1b) was in some cases similar to (1a), and (1c) was nearly negligible; regression uncertainty (1d) indicated that the climate variable changes are often statistically insignificant. In the case of Group 2, uncertainty due to climate sensitivity (2b) dominated for the nearest future, but uncertainty in emission scenarios (2a) attained greater importance later in the 21st century. The mean magnitude of the effect of aerosols on changes in temperature and precipitation was mostly lower than its inter-GCM variability, which was lower than (in the case of the temperature changes) or similar to (in the case of precipitation) the inter-GCM uncertainty in greenhouse gas (GHG) simulations. A stochastic model was developed to assess the combined effect of inter-GCM uncertainty, regression uncertainty, and uncertainty in $\Delta T_{\mathrm{G}}$. While the overall uncertainty in the temperature scenarios was dominated by inter-GCM uncertainty and $\Delta T_{\mathrm{G}}$ uncertainty, the aggregated uncertainty in the precipitation scenarios was dominated by inter-GCM uncertainty only.
\end{abstract}

KEY WORDS: Climate change scenarios • Uncertainty analysis - Global climate models . Pattern scaling

Resale or republication not permitted without written consent of the publisher

\section{INTRODUCTION}

Analyses of the impacts of climate warming on ecosystems and human societies require high-resolution weather data. The set of required weather variables and their spatial and temporal resolution may differ between the systems analysed. For example, crop growth models used in estimating impacts of climate change and climate variability on crop production (Semenov \& Porter 1995, Mearns et al. 1997, Zalud \& Dubrovsky 2002) typically require single-site daily series of extreme temperatures, precipitation amount and solar radiation.

Various approaches can be used to produce weather series representing the changed climate. Most of them rely on Global Climate Models (GCMs). However, as GCMs cannot reliably simulate even the present climate conditions (e.g. annual cycles of the means, see Section 3), the employment of climate change scenarios is better than direct use of a GCM representation of a given future period. Climate change scenarios represent differences in individual variables between some 
plausible future climate and the current or control climate usually represented by a climate model (Houghton et al. 2001), which is usually a GCM or Regional Climate Model (RCM) (Mearns et al. 1997; Giorgi et al. 2004). With a climate change scenario, 2 techniques are typically used to construct the weather series representing the changed climate (Dubrovsky et al. 2000): (1) an observed weather series is modified (additively or multiplicatively) by the scenario parameters (e.g. Maytín et al. 1995; Mearns et al. 1992); (2) a weather series is produced by a weather generator whose parameters have been modified according to the scenario (e.g. Dubrovsky et al. 2000, Riha et al. 1996, Semenov \& Barrow 1997).

GCMs use a set of equations to simulate physical processes in the atmosphere-ocean system (Randall 2000). The most recent versions of GCMs, termed atmosphere-ocean general circulation models (also abbreviated GCMs), couple comprehensive 3-D atmospheric GCMs with ocean GCMs, sea-ice models, and models of land-surface processes. In climate change projections, the GCMs are run with varying environmental conditions, which most commonly reflect changes in concentration of greenhouse gases (GHGs) and aerosols, but also in land use and other factors. The rate of the changes in concentration is based on an emission scenario which follows assumptions made about demographic, industrial and other development. The set of IS92 emission scenarios was considered in the Second Assessment Report of the IPCC (Houghton et al. 1996), and the set of SRES scenarios is commonly used since the release of the Third Assessment Report of the IPCC (Houghton et al. 2001, McCarthy et al. 2001, Metz et al. 2001).

GCM-based climate change scenarios are affected by many uncertainties (see Chapter 13.5 in Houghton et al. 2001). Giorgi \& Francisco (2000) found that the dominant source of uncertainty in the simulation of average regional climate change is due to inter-model variability with inter-scenario (i.e. anthropogenic forcing scenario) and internal model variability playing secondary roles. To account for the uncertainties, use of multiple scenarios in climate change impact studies is widely recommended (e.g. Houghton et al. 2001, Hulme et al. 2002) and adopted (e.g. Alexandrov \& Hoogenboom 2000). This is typically done by using a set of scenarios derived from several GCM simulations (e.g. several GCMs, several runs of a single GCM using different initial conditions, and/or several emission scenarios). Where the pattern scaling technique (Santer et al. 1990) is employed to construct the climate change scenarios, the uncertainties include uncertainty in determining the climate change pattern (Mitchell et al. 1999, Mitchell 2003, Huntingford \& Cox 2000), and uncertainty in estimating the global mean temperature $\left(T_{\mathrm{G}}\right)$, which is often estimated using a simple climate model. The probable range of the change in global mean temperature $\left(\Delta T_{\mathrm{G}}\right)$ is subject to discussion (e.g. Andronova \& Schlesinger 2001, Wigley \& Raper 2001, Gregory et al. 2002, Knutti et al. 2002). For example, Houghton et al. (2001, Chapter 9.3.3) estimate the change to be within 1.55 to $5.95^{\circ} \mathrm{C}$ in 2100 (with respect to the 1961-1990 period).

In this study we assess the uncertainties in climate change scenarios for the territory of the Czech Republic. The scenarios were constructed using the pattern scaling method from the outputs of transient simulations made by 7 GCMs. The data and target areas are described in Section 2. The validation of the GCMs is presented in Section 3. The scenarios and sources of uncertainties are discussed in Section 4.

We treated GCMs as black boxes and do not discuss the results from the point of view of physical processes.

\section{DATA AND TARGET AREAS}

\subsection{GCM data}

The climate change scenarios in this study are based on the transient GCM simulations available from the IPCC-DDC (http://ipcc-ddc.cru.uea.ac.uk) at the beginning of 2001. The resolution of the GCMs, basic characteristics of the emission scenarios used and changes in selected GCM-simulated variables are given in Tables $1 \& 2$. These GCM simulations, which were constructed within the framework of the Coupled Model Intercomparison Project (http://www-pcmdi. llnl.gov/projects/cmip/index.php; Covey et al. 2003), were run using the IS92a or similar emission scenarios. These data have since been superseded by simulations using newer emission scenarios. All GCMs included in the analysis are coupled models with ocean circulation. The horizontal resolution of the atmospheric part of the model ranges from 2.8 to $7.5^{\circ}$ in the zonal direction and from 2.5 to $5.6^{\circ}$ in the meridional direction. The atmospheric models have 9 to 20 levels. Fig. 1 shows the GCM land masks for Europe; note the difference between the ECHAM and NCAR land masks: both models have the same spatial resolution, but the number of land grids is about $50 \%$ greater in NCAR. Grid points that are applicable to the Czech Republic are shown in Fig. 2.

Of the data available from the IPCC-DDC database, the time series of monthly means obtained in 'Greenhouse gas integrations' and 'Greenhouse gas plus sulphate aerosol integrations' were used. These data will be referred to in this paper as GHG and GHG+A integrations, respectively. The integrations start mostly between 1860 and 1901. Historical GHG and sulphate 
Table 1. GCM simulations used in the analysis. Atmospheric resolution: meridional $\times$ zonal. Links to individual model pages available from www.mad.zmaw.de/IPCC_DDC/html/IS92A/index.html

\begin{tabular}{|c|c|c|c|}
\hline Acronym & Model name & $\begin{array}{l}\text { Atmospheric } \\
\text { resolution }\end{array}$ & Emission scenario \\
\hline CCSR & CCSR/NIES & $5.6 \times 5.6^{\circ}$ & 1890-1989: historic $\mathrm{CO}_{2} ;$ 1990-2099: IS92a \\
\hline CGCM & CGCM1 & $3.8 \times 3.8^{\circ}$ & 1900-1989: historic $\mathrm{CO}_{2} ; 1990-2100: 1 \%$ compound increase \\
\hline CSIRO & CSIRO-Mk2 & $3.2 \times 5.6^{\circ}$ & 1881-1989: historic $\mathrm{CO}_{2} ; 1990-2100:$ IS92a \\
\hline ECHAM & ECHAM4/OPYC3 & $2.8 \times 2.8^{\circ}$ & 1860-1989: historic $\mathrm{CO}_{2} ; 1990-2099$ : IS92a \\
\hline GFDL & GFDL-R15-a & $4.5 \times 7.5^{\circ}$ & 1958-2057: $1 \%$ compound increase \\
\hline HadCM & HadCM2 & $2.5 \times 3.75^{\circ}$ & 1860-1989: historic $\mathrm{CO}_{2} ; 1990-2099: 1 \%$ compound increase \\
\hline NCAR & NCAR DOE-PCM & $2.8 \times 2.8^{\circ}$ & Until 1999: historic $\mathrm{CO}_{2}$, 2000-2099: 'business as usual' scenario ( IS92a) \\
\hline
\end{tabular}

Table 2. Changes in global mean temperature $\left(\Delta T_{\mathrm{G}}\right)$, average temperature in the Czech Republic $\left(\Delta T_{\mathrm{CZ}}\right)$, and precipitation in the Czech Republic $\left(\Delta P_{\mathrm{CZ}}\right)$ for 3 periods of the 21st century, based on the greenhouse gas (GHG) GCM simulations. The last column gives change in global mean temperature for doubled effective $\mathrm{CO}_{2}$ (based on 1990) attained in 2066 for the IS92a scenario, and 2054 for $1 \%$ increase of compound $\mathrm{CO}_{2}$

\begin{tabular}{|c|c|c|c|c|c|c|c|c|c|c|c|}
\hline & \multirow{2}{*}{$\begin{array}{c}\text { Emission } \\
\text { scenario }\end{array}$} & \multicolumn{3}{|c|}{ 2010-2039 } & \multicolumn{3}{|c|}{$2040-2069$} & \multicolumn{3}{|c|}{$2070-2099$} & \multirow{2}{*}{$\begin{array}{c}2 \times \mathrm{CO}_{2} \\
\Delta T_{\mathrm{G}} \\
(\%)\end{array}$} \\
\hline & & $\begin{array}{l}\Delta T_{\mathrm{G}} \\
\left({ }^{\circ} \mathrm{C}\right)\end{array}$ & $\begin{array}{l}\Delta T_{\mathrm{CZ}} \\
\left({ }^{\circ} \mathrm{C}\right)\end{array}$ & $\begin{array}{c}\Delta P_{\mathrm{CZ}} \\
(\%)\end{array}$ & $\begin{array}{l}\Delta T_{\mathrm{G}} \\
\left({ }^{\circ} \mathrm{C}\right)\end{array}$ & $\begin{array}{c}\Delta T_{\mathrm{CZ}} \\
\left({ }^{\circ} \mathrm{C}\right)\end{array}$ & $\begin{array}{c}\Delta P_{\mathrm{CZ}} \\
(\%)\end{array}$ & $\begin{array}{l}\Delta T_{\mathrm{G}} \\
\left({ }^{\circ} \mathrm{C}\right)\end{array}$ & $\begin{array}{c}\Delta T_{\mathrm{CZ}} \\
\left({ }^{\circ} \mathrm{C}\right)\end{array}$ & $\begin{array}{c}\Delta P_{\mathrm{CZ}} \\
\left({ }^{\circ} \mathrm{C}\right)\end{array}$ & \\
\hline CCSR & IS92a & 1.12 & 2.11 & 4.4 & 2.08 & 4.15 & 4.6 & 3.00 & 5.85 & 3.7 & 2.6 \\
\hline CGCM & $1 \%$ & 1.47 & 1.20 & +8.0 & 3.01 & 2.39 & 8.7 & 4.93 & 3.83 & 11.0 & 3.2 \\
\hline CSIRO & IS92a & 1.21 & 1.31 & +4.5 & 2.05 & 2.12 & 8.0 & 3.07 & 3.35 & 10.5 & 2.6 \\
\hline ECHAM & IS92a & 1.22 & 1.84 & -6.5 & 2.13 & 3.1 & -1.3 & 3.02 & 4.70 & -3.1 & 2.5 \\
\hline GFDL & $1 \%$ & 1.71 & 2.44 & +0.0 & - & - & - & - & - & - & 2.9 \\
\hline HadCM & $1 \%$ & 1.19 & 1.59 & 1.3 & 2.05 & 2.46 & 0.2 & 3.07 & 3.46 & -2.1 & 2.0 \\
\hline NCAR & IS92a & 0.81 & 0.87 & 3.6 & 1.44 & 1.61 & 3.2 & 2.09 & 2.22 & 8.6 & 1.8 \\
\hline
\end{tabular}

aerosol forcing were applied for the period until 1989, and then the concentrations of compound $\mathrm{CO}_{2}$ and sulphate aerosol in the atmosphere were transiently increased according to the IS92a (or similar) emission scenarios. The 1961-1990 period was used as a baseline for the scenarios, and for validation of the GCMs against observational data. The 90 yr series 2010-2099 (or shorter, when the GCM output ended before 2099), was used to determine the standardised scenarios.

In the case of GHG simulations made by the HadCM model, 4 ensemble members as well as the average of the 4 members were included in the analysis.

The following 4 variables were used from the GCM output: precipitation (PREC), solar radiation (SRAD), daily mean temperature (TAVG), and daily temperature range $(D T R) ; D T R$ is defined as the difference between maximum and minimum daily temperatures. Since $S R A D$ was not available from HadCM, cloudiness was used as a surrogate for determining changes in solar radiation.

\subsection{Target areas}

To develop scenarios for various locations used in Czech impact studies, 4 sites were selected (see Fig. 2):
(A) South Moravia $\left(49^{\circ} \mathrm{N}, 17^{\circ} \mathrm{E}\right)$, which is the warmest part of the Czech Republic and is often used in agricultural impact studies (Dubrovsky et al. 2000, Zalud \& Dubrovsky 2002); (B) South Bohemia $\left(49^{\circ} \mathrm{N}, 14.5^{\circ} \mathrm{E}\right)$, which is used in hydrological impact studies (Buchtele et al. 1999, Hejzlar et al. 2003); (C) Beskydy Mountains $\left(49.5^{\circ} \mathrm{N}, 18.5^{\circ} \mathrm{E}\right)$, where the impacts on forests are being studied (Janous et al. 2003), and (D) Prague $\left(50^{\circ} \mathrm{N}, 15^{\circ} \mathrm{E}\right)$, which represents central Bohemia, where agrometeorological assessments are made.

The changes in the climatic variables in the individual target areas were obtained by linear interpolation of GCM-simulated values for the 4 corners of the GCM grid box in which the target area lies.

\subsection{Observations}

GCMs were validated with 2 types of observational data: (1) 30 yr (1961-1990) series of daily weather characteristics observed at 5 stations within the 'agricultural' target area (Fig. 2), and (2) monthly means interpolated from the $0.5 \times 0.5^{\circ}$ climatology available from the CRU website (http://ipcc-ddc.cru.uea.ac.uk/ obs/get_30yr_means.html). The CRU gridded data were constructed from a station dataset of 1961-1990 


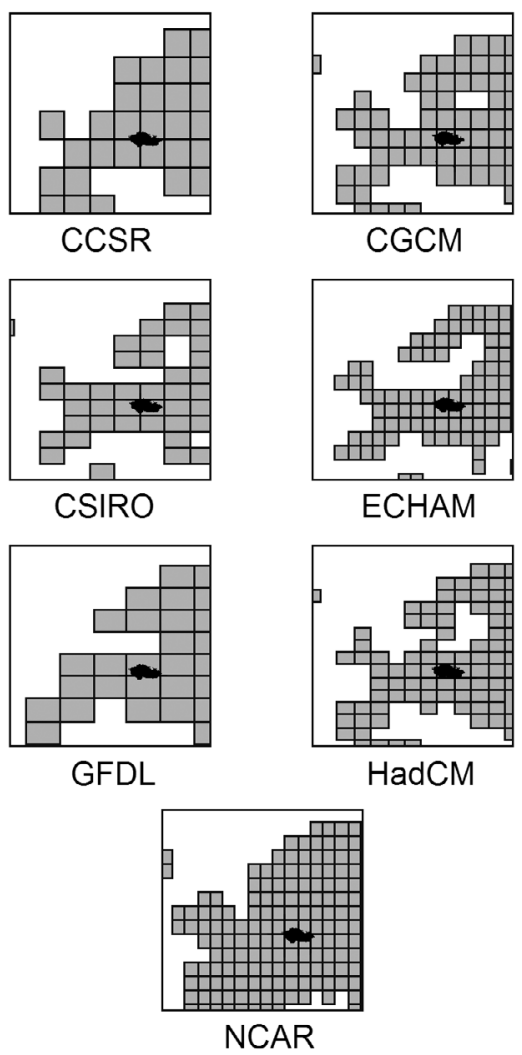

Fig. 1. Land masks (grid boxes) of 7 GCMs over Europe (35 to $75^{\circ} \mathrm{N} \times 15^{\circ} \mathrm{W}$ to $30^{\circ} \mathrm{E}$ ). Black: Czech Republic

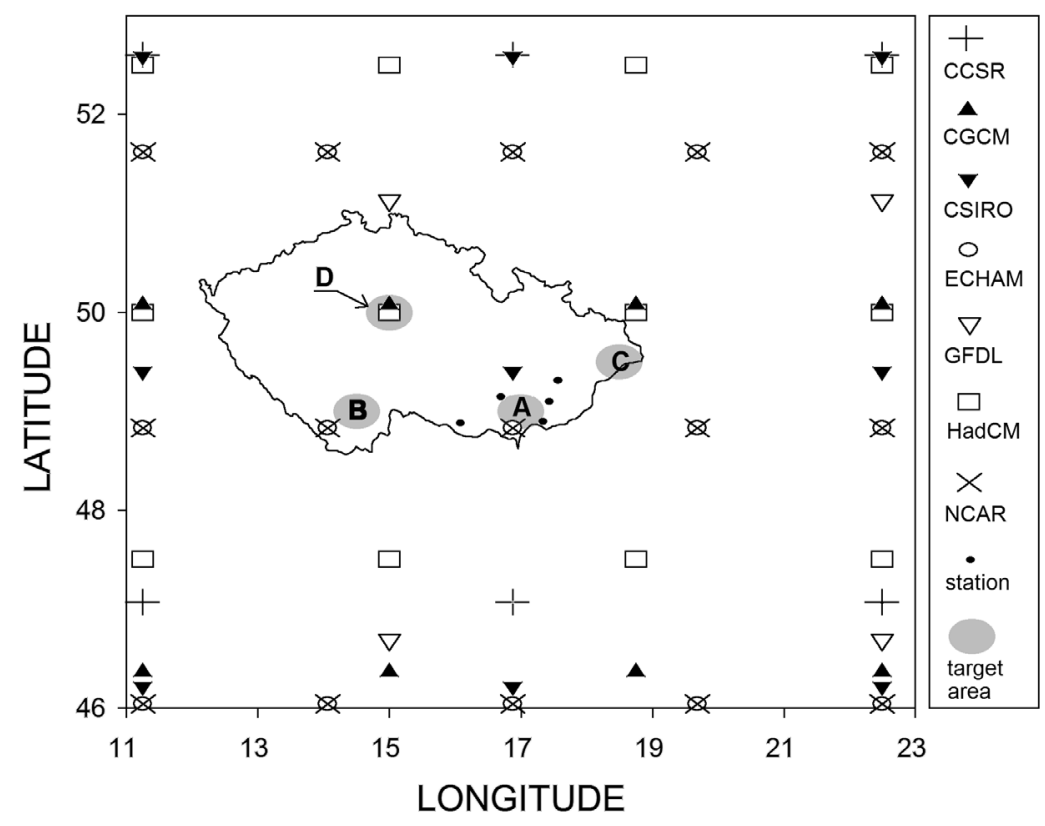

Fig. 2. Centres of GCM grid boxes in or near the Czech Republic. Target areas (grey circles): (A) South Moravia; (B) South Bohemia; (C) Beskydy mountains; (D) Prague; black dots: stations used to validate the GCMs climatological normals. In the Czech Republic, 73 stations were available for supplying $P R E C$ data, 60 for $T E M P$, and 5 for $D T R$ and $S R A D$ (M. New pers. comm.). In developing the CRU climatology, station data were interpolated as a function of latitude, longitude, and elevation using thin-plate splines; see New et al. (1999) for description of the method and validation of the CRU climatology. Although the detailed validation of the CRU data for the Czech territory was not made by the present authors, Fig. 3 indicates that these data conform well with the Czech station data used here, and the differences between the 2 data sources are mostly much smaller than the differences between either of the 2 climatologies and the GCMs. Therefore, the CRU data are considered appropriate for the validation tests presented in the next section.

\section{VALIDATION OF THE GLOBAL CLIMATE MODELS}

The reliability of the scenario derived from a given GCM is related to the ability of the model to simulate the present climate conditions. The performance of individual GCMs may differ for individual climate variables as well as for different regions of the world.

Typically, GCMs are validated for their ability to reproduce spatial patterns (McKendry et al. 1995, Huth 1997) of selected variables and their annual cycles (Nemesova \& Kalvova 1997, Nemesova et al. 1999). GCMs may also be validated in terms of other characteristics, e.g. heat waves (Huth et al. 2000) and autocorrelations of daily extreme temperatures (Kalvova \& Nemesova 1998). In this study, only annual cycles of the monthly means of the 4 variables considered here are validated. Only GHG integrations were considered for the validation tests, as the baseline 1961-1990 annual cycles derived from the GHG and $\mathrm{GHG}+\mathrm{A}$ integrations were found to be very similar (results not shown).

The GCM-based and observed annual cycles for the baseline period are compared in Fig. 3. The gridded data (GCMs and CRU) were linearly interpolated to South Moravia $\left(17^{\circ} \mathrm{E}, 49^{\circ} \mathrm{N}\right)$ for this purpose. The fit of the annual cycles is assessed using several quantitative measures in Table 3. These measures include $B I A S$ (systematic deviation), COR (correlation coefficient between observed and GCM-simulated monthly means), and mean square error with respect to 

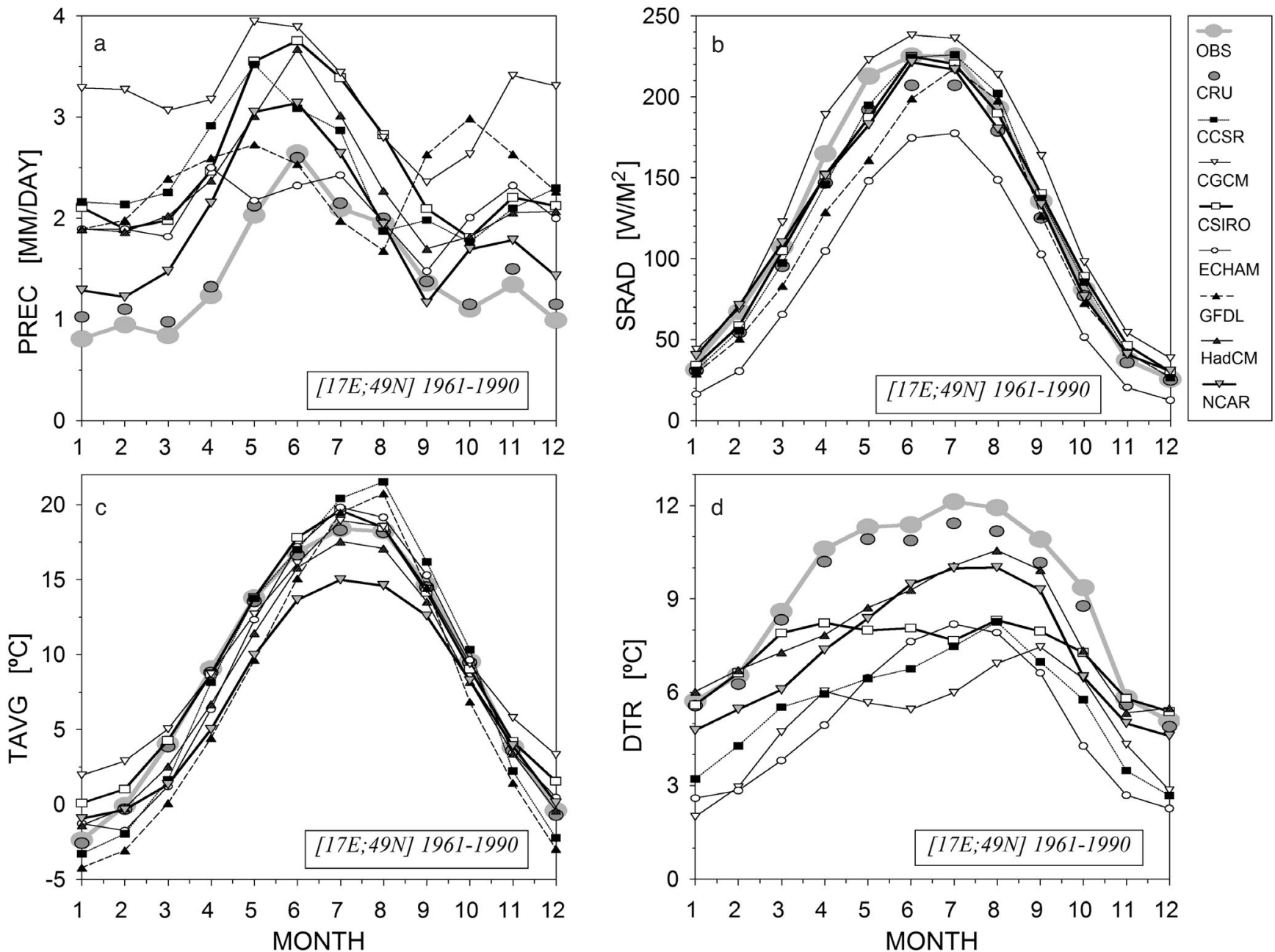

Fig. 3. Validation of GCMs for (a) daily precipitation amount, (b) global solar radiation, (c) daily mean temperature, (d) daily temperature range. HadCM is represented by the ensemble mean of 4 runs. OBS = average of 5 Moravian stations (only 1 station used for $S R A D$ ); $C R U=$ interpolated from the CRU $0.5 \times 0.5^{\circ}$ database

(1) observed monthly means (E1), and (2) observed monthly means corrected for the systematic deviation $(E 2)$. Note that a zero BIAS does not imply perfect fit, and $E 2$ is highly correlated with the correlation coefficient. The lower the value of $E 1$, the better the fit between observed and model-simulated means and in this case, a zero value does imply a perfect fit. Measure $E 2$ is similar to $E 1$, but insensitive to the systematic deviation. Values of COR near 1 indicate that the shapes of the annual cycles are in good agreement irrespective of any systematic deviation or scale factor. Ideally, the $E 1$ measure should be the optimal criterion for selecting the best-performing model. However, to allow for systematic deviations which may result from different definitions of the climatic variables in the various GCMs (e.g. different model level used to represent the surface temperature, or different definition of shortwave radiation), E2 must be considered as well. To show the variability of the fit measures related to the uncertainty of a single GCM, the range of the values related to the 4 members of the HadCM ensemble simulations is also given in Table 3. Although ensemble simulations were available only for HadCM, these results serve as a basis when assessing the significance of differences between individual GCMs.

\subsection{Precipitation (PREC)}

Fig. 3 as well as the measures of fit in Table 3 suggest that the NCAR model performs best in simulating $P R E C$. It yields a satisfactory fit for both mean annual precipitation (measured by the BIAS) and the shape of the annual cycle (measured by $E 1$ ), which exhibits a primary maximum in June and secondary maximum in November. It overestimates the observed precipitation by about $24 \%$, and the correlation coefficient is 0.884 . Higher correlations are achieved by CSIRO and the 
HadCM ensemble mean, but both models overestimate the monthly precipitation means by a larger amount, as indicated by the value of BIAS. GFDL has the poorest performance, with COR near zero. ECHAM and CGCM also do not provide satisfactory results, even though ECHAM has a low mean deviation from the observed cycle.

Table 3. Validation of GCMs in terms of the seasonal cycle of 4 climatic characteristics. Statistics for the HadCM model are mean, minimum and maximum of 4 ensemble members. For $E 1$ and $E 2$, the 3 most successful models are marked by bold and underline (best model), bold only (second best), and underline only (third best), and the poorest model is marked by strikeout. Measures (BIAS, COR, E1,E2) are defined in Section 3. -: not available

\begin{tabular}{|c|c|c|c|c|}
\hline & BIAS & $C O R$ & $E 1$ & $E 2$ \\
\hline \multicolumn{5}{|l|}{ PREC } \\
\hline CCSR & 0.874 & 0.615 & 0.973 & 0.209 \\
\hline CGCM & 1.676 & 0.524 & 3.033 & 0.224 \\
\hline CSIRO & 0.977 & 0.952 & 1.009 & $\underline{0.053}$ \\
\hline ECHAM & 0.527 & 0.492 & 0.481 & 0.203 \\
\hline GFDL & 0.819 & -0.030 & 1.095 & 0.424 \\
\hline \multicolumn{5}{|l|}{ HadCM } \\
\hline Mean & 0.775 & 0.895 & $\underline{0.668}$ & 0.067 \\
\hline Min. & 0.732 & 0.868 & $\overline{0.598}$ & 0.062 \\
\hline Max & 0.813 & 0.901 & 0.749 & 0.088 \\
\hline NCAR & 0.375 & 0.884 & $\underline{0.242}$ & $\underline{0.101}$ \\
\hline \multicolumn{5}{|l|}{$S R A D$} \\
\hline CCSR & 7.643 & 0.997 & $\underline{120.831}$ & $\underline{62.410}$ \\
\hline CGCM & 26.111 & 0.997 & $\overline{773.037}$ & $\overline{91.262}$ \\
\hline CSIRO & 8.369 & 0.997 & 104.409 & $\underline{34.373}$ \\
\hline ECHAM & -26.939 & 0.995 & 817.761 & 92.069 \\
\hline GFDL & -3.434 & 0.983 & 170.900 & 159.109 \\
\hline HadCM $^{a}$ & - & - & - & - \\
\hline NCAR & 6.483 & 0.995 & $\underline{90.387}$ & 48.358 \\
\hline \multicolumn{5}{|l|}{$T A V G$} \\
\hline CCSR & 0.031 & 0.995 & 2.689 & 2.688 \\
\hline CGCM & 1.194 & 0.988 & 4.557 & 3.132 \\
\hline CSIRO & 0.782 & 0.993 & 1.504 & 0.892 \\
\hline ECHAM & -0.123 & 0.984 & 2.010 & 1.995 \\
\hline GFDL & -1.779 & 0.98 & $\overline{7.173}$ & 4.007 \\
\hline \multicolumn{5}{|l|}{ HadCM } \\
\hline Mean & -0.759 & 0.994 & $\underline{1.444}$ & $\underline{0.868}$ \\
\hline Min. & -0.879 & 0.992 & 1.235 & 0.763 \\
\hline Max. & -0.640 & 0.997 & 1.817 & 1.231 \\
\hline NCAR & -1.691 & 0.985 & 6.287 & 3.427 \\
\hline \multicolumn{5}{|l|}{$D T R$} \\
\hline CCSR & -3.116 & 0.965 & 10.433 & $\underline{0.725}$ \\
\hline CGCM & -3.615 & 0.848 & 14.781 & 1.710 \\
\hline CSIRO & -1.450 & 0.932 & $\underline{4.196}$ & 2.095 \\
\hline ECHAM & -3.660 & 0.945 & $1 \overline{4.001}$ & $\underline{0.608}$ \\
\hline GFDL & - & - & - & - \\
\hline \multicolumn{5}{|l|}{ HadCM } \\
\hline Mean & -0.799 & 0.932 & $\underline{1.592}$ & 0.954 \\
\hline Min. & -0.893 & 0.921 & $\overline{1.476}$ & 0.892 \\
\hline Max. & -0.638 & 0.939 & 1.764 & 1.069 \\
\hline NCAR & -1.440 & 0.946 & 2.718 & 0.644 \\
\hline
\end{tabular}

\subsection{Solar radiation $(S R A D)$}

The shape of the annual cycle of $S R A D$ (maximum in June and July) is mostly simulated well. Fig. 3 shows that ECHAM underestimates, CGCM has a rather flat maximum, and GFDL too sharp a maximum in July. HadCM was not assessed, as solar radiation was not available from this model. The most successful models are CSIRO (according to E2) and NCAR (according to $E 1)$, and CCSR performs almost as well.

\subsection{Daily average temperature (TAVG)}

GFDL and CCSR overestimate the amplitude of the annual cycle of TAVG; NCAR underestimates the summer maximum by nearly $3^{\circ} \mathrm{C}$; CGCM overestimates the winter minimum by about $4.5^{\circ} \mathrm{C}$. CSIRO and HadCM are the best models with the lowest mean square error $(E 1)$ and the highest $(>0.99)$ correlation with the observed annual cycle.

\subsection{Diurnal temperature range $(D T R)$}

$D T R$ is generally underestimated by the GCMs. Most models, however, reproduce relatively well the shape of the annual cycle, having its maximum in summer (July-August). ECHAM and CGCM have the greatest systematic error. Omitting the systematic error, the best fit (measured by E2) is achieved by ECHAM, NCAR and CCSR. Except for CGCM, the correlation coefficients always have values greater than 0.9 .

\subsection{Assessment}

Although it is not possible to state objectively which is the 'best overall' model from these results, we identify 3 groups of GCMs according to their ability to reproduce the present annual cycle of the 4 climate variables studied for the Czech Republic. The first group consists of those models which are among the best in simulating at least 2 variables: CSIRO (PREC, $S R A D, T A V G)$, HadCM (PREC, TAVG, DTR), and NCAR (PREC, SRAD); in cases that require a reliable simulation of PREC and DTR, CSIRO and HadCM might be preferred. The second group consists of ECHAM and CCSR, which are about average at reproducing most variables, and the third group contains GFDL and CCCM, which exhibit the poorest performance. However, it must be kept in mind that the validation was for a single location; the performance of the GCMs will be different in other parts of the world, or when overall performance of the models is examined. 


\section{CLIMATE CHANGE SCENARIOS}

\subsection{Introduction}

Site-specific scenarios were developed from each of the $7 \mathrm{GCMs}$ and for each of the 4 target area locations. The scenarios consist of changes in monthly means of $T A V G, D T R, P R E C$ and $S R A D$. In the case of the HadCM model, the change in $S R A D$ was based on the change in cloudiness: $k_{S R A D}=\left(k_{C L O U D}\right)^{-1}$, where $k_{S R A D}$ and $k_{\text {CLOUD }}$ are multiplicative changes in monthly means of global solar radiation and cloud coverage, respectively.

\subsection{Methodology}

The GCMs were run for a limited number of emission scenarios. Alternative techniques are therefore used to develop scenarios for conditions for which a GCM integration is not available. Similarly to other authors (Huntingford \& Cox 2000), statistical postprocessing is applied here to develop a 'standardised' scenario from a given GCM transient run. In developing this scenario, we hypothesised that the climate change pattern (both annual cycle and spatial pattern) is the product of the standardised scenario (which defines the response of the variables to a $1{ }^{\circ} \mathrm{C}$ rise in $T_{\mathrm{G}}$ and $\Delta T_{\mathrm{G}}$. This is the pattern scaling technique (Santer et al. 1990) used in the IPCC First Assessment Report (Mitchell et al. 1990) and subsequently adopted in climate change scenario generators such as SCENGEN (Hulme et al. 1995, 2000); see Houghton et al. (2001; Chapter 13.5.2.1) for further references. Mitchell et al. (1999) and Mitchell (2003) examined the applicability of the technique for estimating spatial patterns of change in annual and summer temperature and precipitation. They used output from the HadCM2 model and found that the technique worked better for temperature than for precipitation, and for annual means than for summer means. Huntingford \& Cox (2000) examined applicability of the technique for 9 surface and near-surface weather variables. They used the HadCM3 model and found that it performed best for temperature and solar radiation, and poorest for precipitation. They also tested the transferability of the patterns between different emission scenarios; their results indicate that patterns should not be scaled by factors related to the radiative forcing if this forcing exceeds that used in deriving the standardised scenario. Mitchell et al. (1999) pointed out that patterns derived from simulations of GHG only should not be combined with scaling factors based on emission scenarios with strong aerosol forcing.
In the simplest approach, the standardised scenario may be determined by dividing the scenario related to a selected period by $\Delta T_{\mathrm{G}}$ predicted by a given model for that period. To make use of a longer portion of the GCM integration, we determine the standardised scenario as the weighted average of the series of scenarios derived from several consecutive $10 \mathrm{yr}$ slices. In particular, the standardised scenario is obtained from the transient run by a linear regression (passing through zero), in which the independent variable is $\Delta T_{\mathrm{G}}$, and the dependent variable is the change of a given variable in a given month, $\Delta y_{m}$. The regression is applied to the 9 points for the $10 \mathrm{yr}$ slices from 2010 to 2099. This regression procedure averages the scenario over the entire period (which conforms to the idea that the standardised scenario is an average response of local climate to a $1^{\circ} \mathrm{C}$ rise in $T_{\mathrm{G}}$ ). Standardised scenarios of the 4 variables based on the $7 \mathrm{GCMs}$ and averaged over the 4 target areas are shown in Fig. 4 . Having obtained the standardised scenario, the climate change scenario for any period and any emission scenario for which $\Delta T_{\mathrm{G}}$ can be estimated, is determined as

$$
\Delta y_{m}=\Delta_{\mathrm{S}} y_{m} \times \Delta T_{\mathrm{G}}
$$

where $\Delta_{\mathrm{S}} y_{m}$ is the standardised change in the variable $y$ for month $m$, and $\Delta y_{m}$ is the change in $y$ resulting from $\Delta T_{\mathrm{G}}$.

In this study, the $\Delta T_{\mathrm{G}}$ values were estimated by the simple 1-dimensional climate model MAGICC (Harvey et al. 1997, Hulme et al. 2000), which is available from the CRU web page (http://www.cru.uea.ac.uk/ $\sim$ mikeh/software/). The specific model used in MAGICC is described in Wigley \& Raper (1987, 1992, 1993) and Raper et al. (1996). In MAGICC a given emission scenario is converted to GHG and aerosol concentrations and radiative forcing, and the resulting $\Delta T_{\mathrm{G}}$ and sea level are estimated using the climate sensitivity factor defined in Section 4.3.3. MAGICC has been used in many impact studies (Goldammer \& Price 1998, Kont et al. 2003) and in the Second and Third IPCC Assessment Reports (Gates et al. 1996, Houghton et al. 2001). Instead of using a simple climate model, the GCM-based standardised scenario could also be scaled by $\Delta T_{\mathrm{G}}$ simulated by the same GCM (see Table 2 for the values of $\Delta T_{\mathrm{G}}$ for selected periods). Applicability of the pattern scaling technique is conditioned by the assumption that changes in climatic variables are proportional to $\Delta T_{\mathrm{G}}$ (see Section 4.3.2).

\subsection{Uncertainties in the climate change scenario}

Where pattern scaling is employed to specify the scenario, the uncertainties are divided into 2 groups: (1) Uncertainties that have an effect on the shape of the 

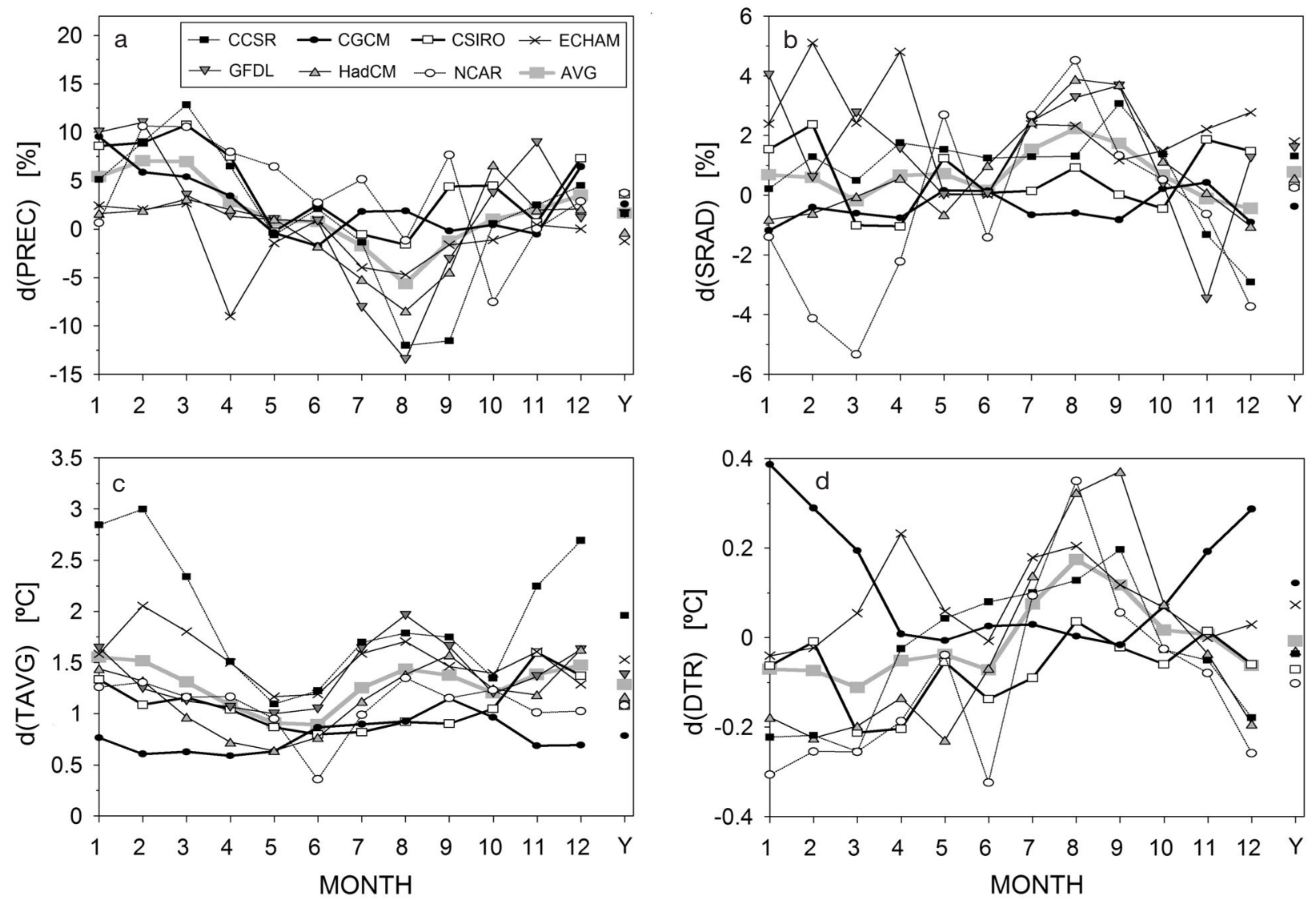

Fig. 4. Standardised GCM-based climate change scenarios for the Czech Republic: (a) precipitation, (b) solar radiation, (c) daily mean temperature, (d) daily temperature range. ' $\mathrm{Y}$ ' on $\mathrm{X}$-axis: changes in annual mean. AVG: scenario averaged over all 7 models. See Table 1 for model acronyms

standardised scenario (Sections 4.3.1. and 4.3.2.): interGCM uncertainty (differences between individual GCMs), internal uncertainty of a given GCM, and uncertainty related to the regression technique used to determine the standardised scenario; to indicate how the climate change scenario differs for various locations in the Czech Republic, the variability at the 4 target areas is also included in this first group ('choiceof-site' uncertainty). (2) Uncertainties in estimating $\Delta T_{\mathrm{G}}$ (Section 4.3.3), which is used to multiply the standardised scenario; this includes uncertainties in 2 input parameters of the MAGICC model: choice of an emission scenario and climate sensitivity factor. In addition, uncertainty related to the effect of aerosols, which affects both the shape of the standardised scenario and the value of $\Delta T_{\mathrm{G}}$, is estimated in Section 4.3.4.

\subsubsection{Uncertainties affecting seasonal patterns}

Changes in the 4 climatic variables projected by the 7 GCMs are shown in Fig. 4. Although the scenarios derived from individual GCMs differ, there exist some common features: (1) In the case of the change in $T A V G$, a good agreement exists between most models; except in CGCM (lowest change) and CCSR (highest change), the predicted annual mean temperature increase resulting from a $1^{\circ} \mathrm{C}$ rise in $T_{\mathrm{G}}$ ranges from 1 to $1.5^{\circ} \mathrm{C}$. (2) $D T R$ slightly increases in summer and slightly decreases (except for CGCM) in winter. (3) PREC increases in winter, but decreases in summer. (4) $S R A D$ increases in summer, and great uncertainty exists between GCMs in winter.

Fig. 5 compares uncertainties related to (1) the choice of GCM (inter-GCM uncertainty), (2) intraGCM variability (represented by the variability of the 4 runs of the HadCM ensemble simulations), (3) variability over the 4 target areas and (4) regression technique (discussed in Section 4.3.2.). As the numbers of set members from which the variability is calculated are very low, the results should be used with caution. Nonetheless, Fig. 5 shows: (1) Uncertainty due to choice of site has mostly a negligible effect on the magnitude of change and on the shape of the annual cycle of change; therefore, the single climate change 

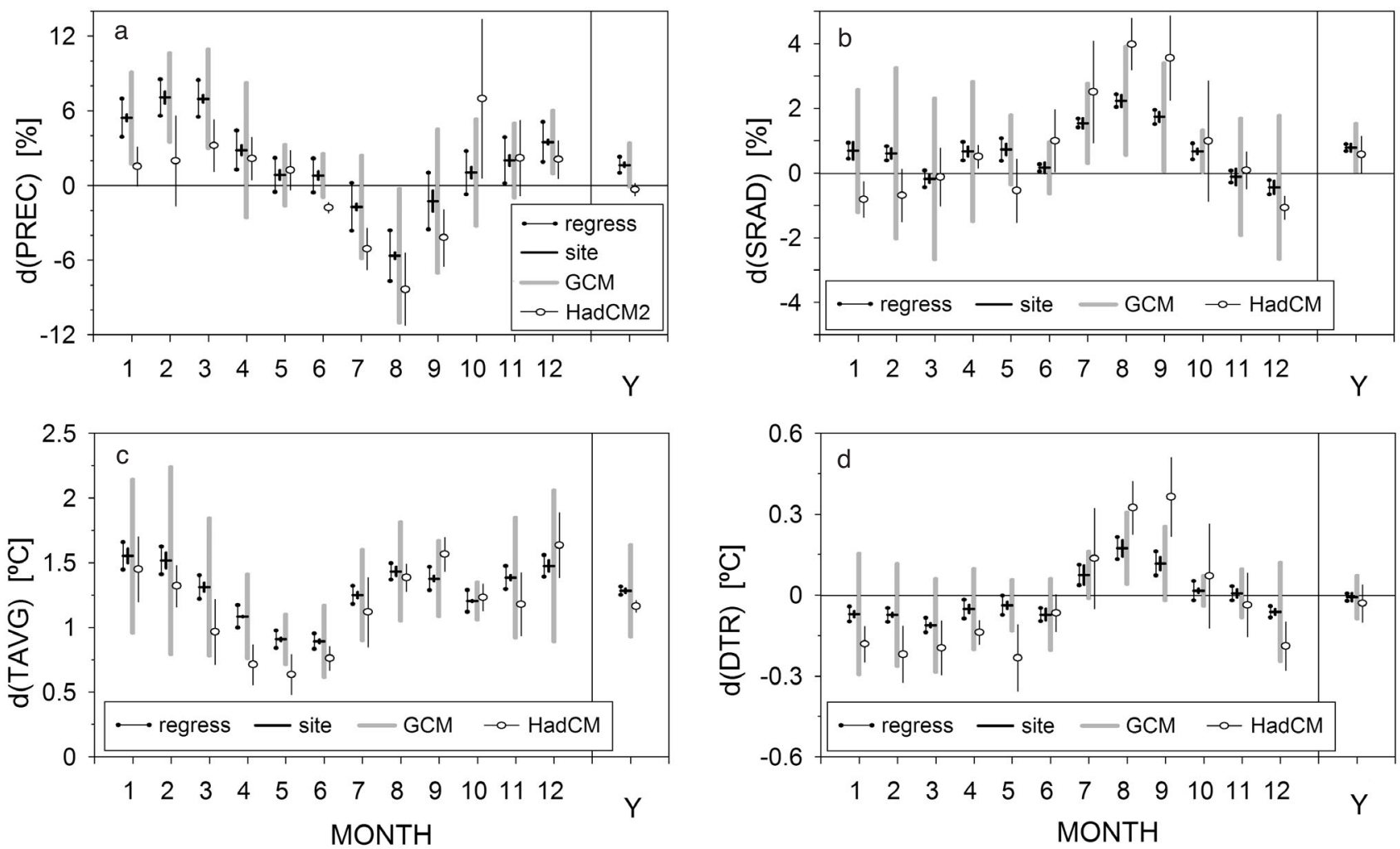

Fig. 5. Uncertainties for changes in (a) precipitation, (b) solar radiation, (c) daily mean temperature, (d) daily temperature range, due to (1) the regression involved in determining the standardised scenario ('regress'), (2) choice of site, (3) choice of model ('GCM'), (4) internal variability of the HadCM model ('HadCM'). Vertical bars denote, in 'regress': standard error of the linear regression coefficient; in the other 3 cases: mean \pm SD range, in site uncertainty calculated from the AVG scenarios for the target areas, in GCM uncertainty from the 7 GCM-based scenarios, and in internal variability of HadCM from the 4

HadCM scenarios

scenario is representative of the entire Czech Republic. (2) Choice of GCM has a significant effect on both the magnitude of change and shape of the annual cycle of changes; for example, the ECHAM-based scenario represents a warmer and drier climate, while the NCAR-based scenario represents a lower increase in temperature and a wetter climate. (3) Intra-GCM uncertainty is mostly lower than inter-GCM variability (which agrees with the results of Giorgi \& Francisco 2000); however, intra-GCM uncertainty is sometimes similar to or larger than inter-GCM uncertainty, indicating that differences between GCMs can be dominated by their internal variability.

\subsubsection{Uncertainty in the pattern scaling technique}

The pattern scaling technique assumes a linear relationship between $\Delta T_{\mathrm{G}}$ and changes in the site-specific climatic variables (Eq. 1). The coefficient of proportionality (i.e. the slope parameter, or the standardised change in a given variable) is determined by a linear regression applied to the GCM output series (Section 4.2).
Therefore, the reliability of the pattern scaling technique may in part be quantified by the error involved in determining the slope parameter and/or by the level of significance at which we reject the hypothesis that the slope parameter for a given variable in a given month is zero. The lower the error in the slope parameter, the greater is the probability of rejecting the null hypothesis and the higher is the reliability of the pattern scaling technique. Uncertainty due to the regression (averaged over all GCMs) is shown in Fig. 5 ('regress' bars capped by black circles) and the statistical significance of monthly changes is in Table 4, which shows the number of months for which the null hypothesis is rejected at the 0.05 level.

The results show: (1) The relative errors involved in determining the regression coefficients are lowest for $T A V G$; the null hypothesis is rejected for all months and all GCMs. On the other hand, relative errors involved in determining the standardised changes in the other 3 variables are much higher and the null hypothesis is accepted in $48 \%$ (for $P R E C$ ) to $58 \%$ (for $D T R$ ) of months (averaged over all $7 \mathrm{GCMs}$ ). The greatest errors - showing the lowest correlation with 
Table 4. Test of the significance of monthly changes in 4 climatic characteristics. Number of months per year in which the change in monthly mean is significantly different from zero $(p=0.05)$. AVG4 is the number of months averaged over all 4 variables, AVG7 is the number of months averaged over all GCMs. See Table 1 for the model acronyms; H1, H2, H3, H4 denote the 4 ensemble runs of the HadCM model. -: not available

\begin{tabular}{|lccccc|}
\hline & PREC & SRAD & TAVG & DTR & AVG4 \\
\hline GCM & & & & & \\
CCSR & 8 & 8 & 12 & 9 & 9.25 \\
CGCM & 5 & 6 & 12 & 7 & 7.50 \\
CSIRO & 6 & 7 & 12 & 4 & 7.25 \\
ECHAM & 3 & 6 & 12 & 5 & 6.50 \\
GFDL & 3 & 3 & 12 & - & 6.00 \\
HadCM & 9 & 8 & 12 & 10 & 9.75 \\
NCAR & 7 & 6 & 12 & 7 & 8.00 \\
AVG7 & 5.86 & 6.29 & 12.00 & 7.00 & 7.75 \\
HadCM & & & & & \\
H1 & 4 & 7 & 12 & 4 & 6.75 \\
H2 & 5 & 8 & 12 & 8 & 8.25 \\
H3 & 7 & 5 & 12 & 6 & 7.50 \\
H4 & 5 & 7 & 12 & 9 & 8.25 \\
\hline
\end{tabular}

$\Delta T_{\mathrm{G}}$ - are associated with changes in PREC. This agrees with the results of Mitchell et al. (1999), who found that many regional precipitation changes were not statistically significant. (2) Uncertainty in annual means is lower than uncertainty in monthly means. (3) Furthermore, there exist differences between individual GCMs: The smallest errors (implying higher frequency in rejecting the null hypothesis) occur in the ensemble mean of HadCM; errors involved in the single members of the ensemble (rows H1 to H4) show errors comparable with other GCMs. The patterns derived from the ensemble mean of HadCM have higher significance because internal variability is partly smoothed out in the ensemble mean. Our finding also agrees with results in Mitchell et al. (1999), who found that the sampling error in the mean of 4 HadCM2 simulations is about half as high as in a single simulation. The single run of the CCSR model exhibits nearly the same level of proportionality as the HadCM ensemble mean. It should, however, be stressed that the errors involved in determining the standardised scenario do not say anything about the reliability of the GCMs, as they only quantify the applicability of the pattern scaling technique. The technique appears to be applicable to temperature changes; applicability to the other 3 variables is problematic.

In comparison with the uncertainties discussed in Section 4.3.1., we conclude that the magnitude of the uncertainty due to the regression technique is greater than the choice-of-site uncertainty, but lower than the inter-GCM uncertainty.

\subsubsection{Uncertainties in the scaling factor}

The $\Delta T_{\mathrm{G}}$ values determined by the MAGICC model for selected emission scenarios and climate sensitivities are shown in Fig. 6 and the values for selected years and $\mathrm{CO}_{2}$ concentrations in Table 5.

Emission scenario (without consideration of aerosols). There exists a variety of emission scenarios based on different assumptions about future socio-economic developments. In the IS92 scenarios, the $\mathrm{CO}_{2}$ concentration rises from $354 \mathrm{ppm}$ in 1990, to between 471 (IS92c) and 949 ppm (IS92e) in 2100. In the newer SRES scenarios (A1, A2, B1 and B2) developed for the IPCC Third Assessment Report, the range of $\mathrm{CO}_{2}$ concentrations in 2100 is narrower: from 548 (Scenario B1) to $826 \mathrm{ppm}$ (Scenario A2). The range of the emission scenarios entails a range of $\Delta T_{\mathrm{G}}$ values (Fig. 6), which widens towards the end of the 21st century: Assuming intermediate climate sensitivity and no aerosol effect, the ratio of $\Delta T_{\mathrm{G}}$ values related to the IS92e and IS92C scenarios increases from 1.32 in 2025 to 2.44 in 2100. The range of the changes related to the 4 SRES scenarios is lower, as the ratio of the highest (SRES-A2) to the lowest (SRES-B1) scenarios increases from 1.14 in 2025 to 1.72 in 2100.

Climate sensitivity. The equilibrium climate sensitivity parameter (hereafter referred to as 'climate sensitivity', $\Delta T_{2 \times}$ ) usually refers to the equilibrium change in $T_{\mathrm{G}}$ following a doubling of the atmospheric (equivalent) $\mathrm{CO}_{2}$ concentration. Due to the inertia of the climate system, the temperature re-

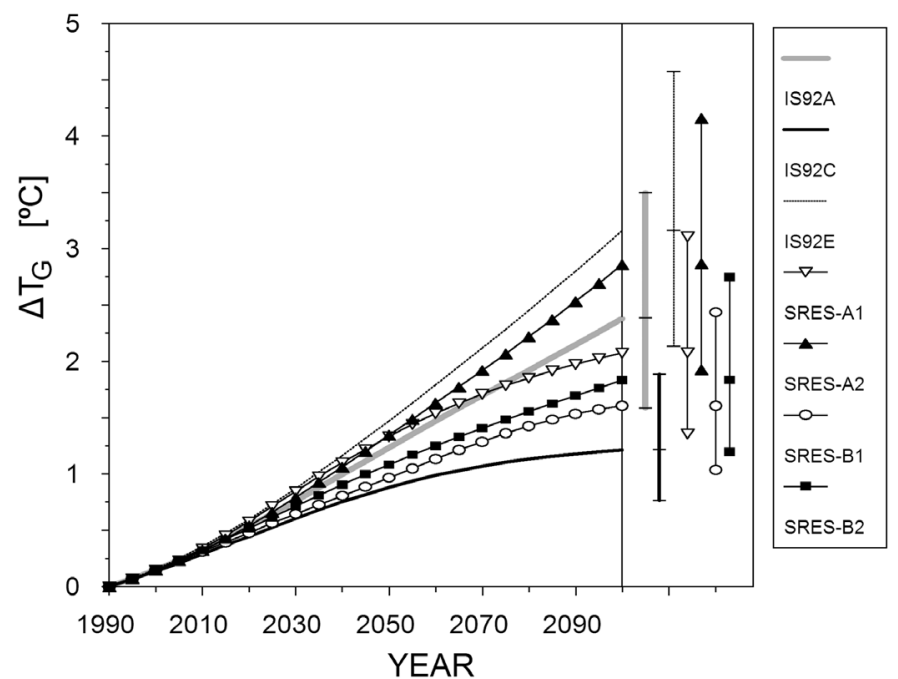

Fig. 6. Change in global mean temperature calculated by the simple climate model MAGICC for 7 emission scenarios. The curves relate to 3 IS92 scenarios and 4 SRES scenarios using the intermediate climate sensitivity $\left(2.5^{\circ} \mathrm{C}\right)$. Vertical bars in the right part of the graph demarcate $\Delta T_{\mathrm{G}}$ in 2100 related to low/intermediate/high climate sensitivity $\left(\Delta T_{2 \times}=1.5,2.5\right.$ and $4.5^{\circ} \mathrm{C}$ ). Effect of aerosols is not considered 
Table 5. Changes in global mean temperature, $\Delta T_{\mathrm{G}}$ calculated by the MAGICC model. Baseline period: 1961-1990; baseline $\mathrm{CO}_{2}$ level: $333 \mathrm{ppm}$. Climate sensitivities: low $\Delta T_{2 \times}=1.5^{\circ} \mathrm{C}$; intermediate $\Delta T_{2 \times}=2.5^{\circ} \mathrm{C}$; high $\Delta T_{2 \times}=4.5^{\circ} \mathrm{C}$. Only the effect of greenhouse gases is considered. The MAGICC climate model does not run beyond 2100, and values of $\Delta T_{\mathrm{G}}$ are not available (-) when the required $\mathrm{CO}_{2}$ concentration is attained after 2100. Bold: $\mathrm{CO}_{2}$ level (ppm) attained in the given year; bold italic: year in which the given $\mathrm{CO}_{2}$ level is attained

\begin{tabular}{|c|c|c|c|c|c|c|}
\hline Emission scenario & Climate sensitivity & 2025 & 2050 & 2100 & $1.5 \times \mathrm{CO}_{2}$ & $2 \times \mathrm{CO}_{2}$ \\
\hline \multirow[t]{4}{*}{ IS92C } & & 412 & 447 & 471 & $>2100$ & $>2100$ \\
\hline & Low & 0.46 & 0.70 & 0.90 & - & - \\
\hline & Intermediate & 0.66 & 1.02 & 1.35 & - & - \\
\hline & High & 0.92 & 1.45 & 2.02 & - & - \\
\hline \multirow[t]{4}{*}{ IS92a } & & 433 & 510 & 706 & 2047 & 2092 \\
\hline & Low & 0.55 & 0.95 & 1.72 & 0.90 & 1.59 \\
\hline & Intermediate & 0.78 & 1.37 & 2.52 & 1.30 & 2.33 \\
\hline & High & 1.09 & 1.93 & 3.63 & 1.83 & 3.36 \\
\hline \multirow[t]{4}{*}{ IS92e } & & 450 & 562 & 949 & 2037 & 2068 \\
\hline & Low & 0.62 & 1.12 & 2.27 & 0.85 & 1.52 \\
\hline & Intermediate & 0.87 & 1.61 & 3.30 & 1.21 & 2.19 \\
\hline & High & 1.20 & 2.25 & 4.71 & 1.68 & 3.09 \\
\hline \multirow[t]{4}{*}{ SRES-B1 } & & 420 & 467 & 548 & 2065 & $>2100$ \\
\hline & Low & 0.49 & 0.76 & 1.17 & 0.92 & - \\
\hline & Intermediate & 0.70 & 1.11 & 1.74 & 1.35 & - \\
\hline & High & 0.98 & 1.57 & 2.57 & 1.94 & - \\
\hline \multirow[t]{4}{*}{ SRES-A2 } & & 438 & 535 & 826 & 2041 & 2077 \\
\hline & Low & 0.56 & 1.03 & 2.06 & 0.86 & 1.56 \\
\hline & Intermediate & 0.80 & 1.48 & 3.00 & 1.23 & 2.27 \\
\hline & High & 1.10 & 2.08 & 4.29 & 1.71 & 3.22 \\
\hline
\end{tabular}

sponse of transient GCM simulations to doubled $\mathrm{CO}_{2}$ generally decreases with increasing rate of $\mathrm{CO}_{2}$ rise and is therefore always lower than the climate sensitivity. The value of the climate sensitivity factor is the subject of much discussion. According to the IPCC (Houghton et al. 2001), the value is likely to be in the range 1.5 to $4.5^{\circ} \mathrm{C}$ (no confidence interval is stated) with $2.5^{\circ} \mathrm{C}$ being the best estimate. Andronova \& Schlesinger (2001) used a simple climate/ ocean model, the observed near-surface temperature record, and a bootstrap technique to estimate the probability density function for $\Delta T_{2 \times i}$ they found that due to natural variability and uncertainty in radiative forcing, the $90 \%$ confidence interval for $\Delta T_{2 \times}$ is 1.0 to $9.3^{\circ} \mathrm{C}$. This implies a $54 \%$ likelihood that $\Delta \mathrm{T}_{2 \times}$ lies outside the IPCC range. Based on several sources (including Andronova \& Schlesinger 2001), Wigley \& Raper (2001) assigned 90\% confidence to the IPCC's 1.5 to $4.5^{\circ} \mathrm{C}$ range.

In this study we used the 3 values of climate sensitivity proposed by the IPCC: Low $=1.5^{\circ} \mathrm{C}$ intermediate $=2.5^{\circ} \mathrm{C}$ High $=4.5^{\circ} \mathrm{C}$. The range of values of $\Delta T_{\mathrm{G}}$ related to climate sensitivities within the 1.5 to $4.5^{\circ} \mathrm{C}$ interval is illustrated in Fig. 6 by the vertical bars at right. The values of $\Delta T_{\mathrm{G}}$ in Table 5 imply that the ratio of the $T_{\mathrm{G}}$ changes related to High vs. Low climate sensitivities is within 1.9 to 2.25 for various emission scenarios and time projections.
Summary. Both the choice of the emission scenario and the climate sensitivity factor are significant sources of uncertainty in estimating $\Delta T_{\mathrm{G}}$. In the case of the IS92 scenarios, the ratio of $\Delta T_{\mathrm{G}}$ values related to the high and low emission scenarios is lower than the ratio of values related to the high and low climate sensitivities in the first half of this century, but higher at the end of the century. The range related to the 4 SRES scenarios is lower (in comparison to the IS92 scenarios) and the uncertainty due to the climate sensitivity dominates also at the end of the century. It should, however, be noted that some SRES scenarios fall outside the range of the 4 SRES scenarios considered here. For example, the SRES-A1FI scenario, which is the 'fossil intensive' version of the SRES-A1 scenario, implies a 12 to $15 \%$ increase in radiative forcing in the second half of the 21 st century, resulting in a temperature rise that is 12 to $15 \%$ higher than under the SRES-A2 scenario.

\subsubsection{Effect of aerosols}

Atmospheric aerosols affect the transmittance of radiation through the atmosphere, and thus temperature and other climatic characteristics. The direct radiative effect of the aerosols relates to scattering and absorption of solar and infrared radiation in the atmo- 
sphere, and the indirect effect is broadly defined as the overall process by which aerosols perturb the earth-atmosphere radiation balance by modulation of cloud albedo and cloud amount (Houghton et al. 2001, Chapter 5). Unlike the majority of the GHGs, the effect of which does not depend on the geographical distribution of their sources, aerosol effects will be much more region-specific, and this makes their assessment more complex. In this study, we used the pattern scaling technique and assessed aerosol effects in 2 stages: effect on the pattern (standardised scenario), and effect on $\Delta T_{\mathrm{G}}$.

Effect on seasonal patterns. This was assessed by comparing scenarios derived from GHG with GHG+A simulations. Simulations made with $6 \mathrm{GCMs}$ were included in the analysis; NCAR was excluded, as the GHG plus GHG+A pair of simulations was not available. Fig. 7 shows the differences between the GHG and GHG+A scenarios for TAVG and PREC, while the vertical bars represent the variability of this differ-
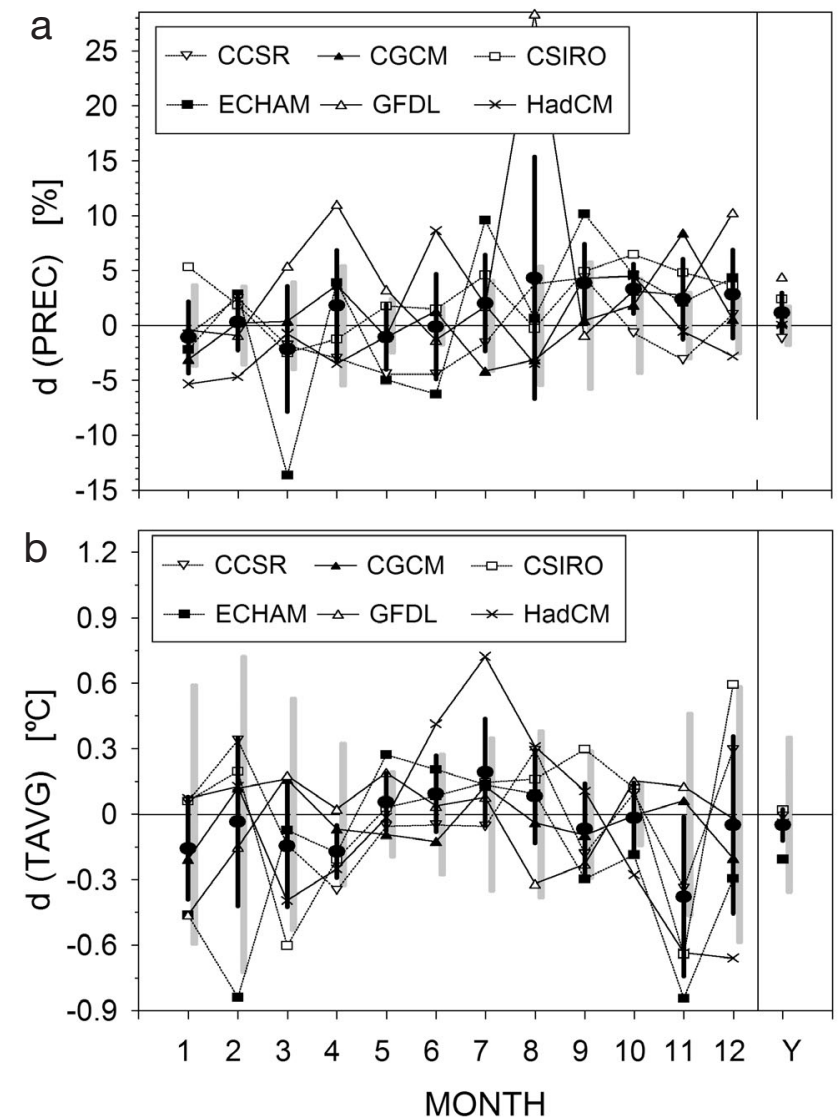

Fig. 7. Differences between standardised scenarios based on GHG+A and GHG simulations: (a) daily precipitation amount, (b) daily mean temperature. Lines represent differences related to 6 GCMs and vertical black bars with black circles show mean $\pm \mathrm{SD}$. Grey vertical bars centred around the $x$ axis indicate uncertainty related to the choice of GCM. See Table 1 for the model acronyms ence. Averaged over all GCMs, the effect of aerosols on temperature change is slightly negative (positive in summer, negative during the rest of the year) and the effect on the precipitation change is rather indistinct in the first half of the year and positive in the second half of the year. Note, however, that this relates to the standardised changes. Considering the effect of aerosols on the predicted $\Delta T_{\mathrm{G}}$ for the IS92a emission scenario (Fig. 8), the overall effect of aerosols on the temperature change is negative for all months of the year.

The statistical significance of the aerosol effect was tested for each GCM, each variable and each month of the year (Table 6), on the basis of the standardised changes in individual monthly climatic characteristics and their standard errors. Differences between GHG and GHG+A are mostly significant, and the significance level is similar for all variables, months and GCMs. In spite of this, Fig. 7 shows that the aerosol effect is associated with great uncertainty, as the mean magnitude of the aerosol effect is mostly lower than its inter-GCM variability, which is lower than (in the case of the temperature changes) or comparable with (precipitation) the inter-GCM uncertainty in GHG simulations (grey vertical bars).

Effect on $\Delta T_{\mathrm{G}}$. The values of $\Delta T_{\mathrm{G}}$ were calculated by the MAGICC model. This model considers 3 aspects of aerosol forcing: direct and indirect forcing from fossil fuel emissions and forcing from biospheric emissions (details in Wigley \& Raper 1992, Raper et al. 1996). The difference in $\Delta T_{\mathrm{G}}$ with and without aerosols is shown in Fig. 8. In accordance with the expected increase of sulphate emissions in the IS92 scenarios, the effect of

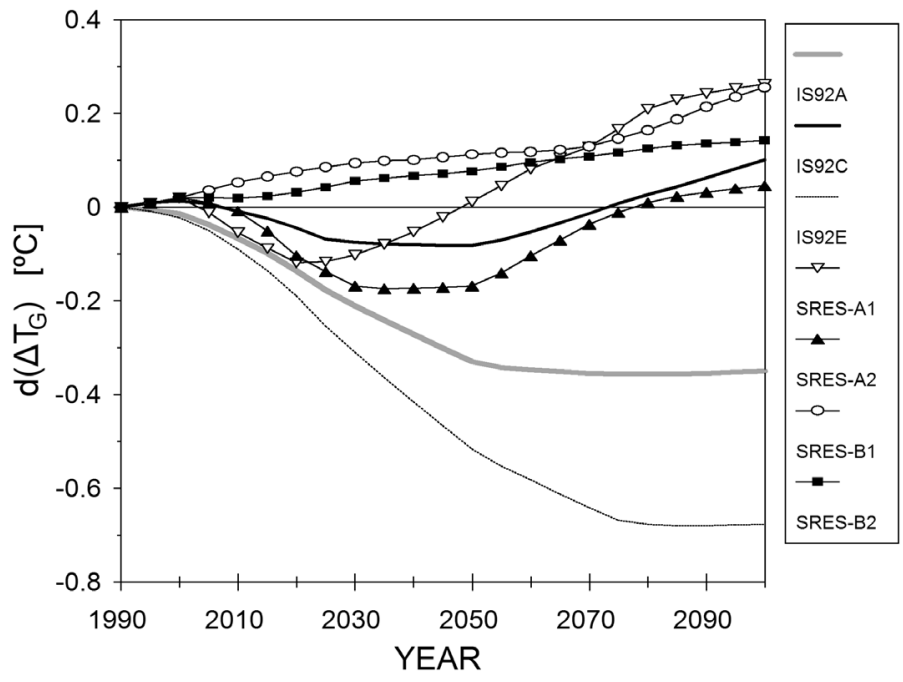

Fig. 8. Effect of changes in atmospheric aerosol concentration on change in global mean temperature $\left(\Delta T_{\mathrm{G}}\right)$ according to the MAGICC model, for intermediate climate sensitivity $\left(2.5^{\circ} \mathrm{C}\right) . \mathrm{d}\left(\Delta T_{\mathrm{G}}\right)$ : difference in $\Delta T_{\mathrm{G}}$ with respect to 1990 , simulated with and without the effects of aerosols 
Table 6. Comparison of Simulations GHG (greenhouse gas) vs GHG+A (greenhouse gas + aerosol) in the 4 GCMs for which the simulations run until the end of the 21st century: number of months in which the difference between GHG and GHG+A scenarios is statistically significant $(p=0.05)$ in each season (DJF, MAM, JJA, SON) and the whole year. $\alpha$ is the minimum value of the level of significance at which we reject the hypothesis that changes in the annual mean are significantly different between GHG and GHG+A (the lower the value of $\alpha$, the more significant is the difference) $+/-$ after $\alpha$ indicates that the GHG+A change is greater/lower than the GHG change. See Table 1 for the model acronyms

\begin{tabular}{|c|c|c|c|c|c|}
\hline & PREC & $S R A D$ & $T A V G$ & $D T R$ & SUM \\
\hline \multicolumn{6}{|l|}{ CCSR } \\
\hline Year & 7 & 8 & 6 & 5 & 26 \\
\hline DJF & 1 & 3 & 2 & 1 & 7 \\
\hline MAM & 3 & 3 & 1 & 1 & 8 \\
\hline JJA & 1 & 1 & 1 & 1 & 4 \\
\hline SON & 2 & 1 & 2 & 2 & 7 \\
\hline$\alpha(\%)$ & $3-$ & $0+$ & $80-$ & $93-$ & \\
\hline \multicolumn{6}{|l|}{ CGCM } \\
\hline Year & 7 & 11 & 9 & 8 & 35 \\
\hline DJF & 1 & 3 & 3 & 3 & 10 \\
\hline MAM & 2 & 2 & 3 & 2 & 9 \\
\hline JJA & 2 & 3 & 2 & 0 & 7 \\
\hline SON & 2 & 3 & 1 & 3 & 9 \\
\hline$\alpha(\%)$ & $29+$ & $0+$ & $0-$ & $0+$ & \\
\hline \multicolumn{6}{|l|}{ CSIRO } \\
\hline Year & 9 & 7 & 10 & 8 & 34 \\
\hline DJF & 2 & 2 & 2 & 2 & 8 \\
\hline MAM & 2 & 2 & 2 & 1 & 7 \\
\hline JJA & 2 & 1 & 3 & 2 & 8 \\
\hline SON & 3 & 2 & 3 & 3 & 11 \\
\hline$\alpha(\%)$ & 0 & $0-$ & $7+$ & $0-$ & \\
\hline \multicolumn{6}{|l|}{ HadCM } \\
\hline Year & 8 & 8 & 8 & 7 & 31 \\
\hline DJF & 3 & 2 & 1 & 3 & 9 \\
\hline MAM & 1 & 2 & 2 & 1 & 6 \\
\hline JJA & 2 & 3 & 3 & 2 & 10 \\
\hline SON & 2 & 1 & 2 & 1 & 6 \\
\hline$\alpha(\%)$ & $90+$ & $0-$ & $24-$ & $0+$ & \\
\hline \multicolumn{6}{|l|}{ Total } \\
\hline Year & 31 & 34 & 33 & 28 & 126 \\
\hline DJF & 7 & 10 & 8 & 9 & 34 \\
\hline MAM & 8 & 9 & 8 & 5 & 30 \\
\hline JJA & 7 & 8 & 9 & 5 & 29 \\
\hline SON & 9 & 7 & 8 & 9 & 33 \\
\hline
\end{tabular}

aerosols is negative (cooling), except for the IS92c scenario, in which the aerosols contribute to warming at the end of the 21st century; this is because the aerosol emissions are assumed to decrease in the IS92c scenario, so that the atmospheric aerosol concentration falls below the present state. Due to the recently reconsidered prognosis of future development in aerosol emissions (Nakicenovic \& Swart 2000), the net effect of aerosols in the SRES scenarios on $\Delta T_{\mathrm{G}}$ is positive (SRES-B1 and SRES-B2), or initially negative and later positive (SRES-A1 and SRES-A2).

\subsubsection{Combining the uncertainties}

What is the combined effect of all these uncertainties? We employed the uncertainties based on the GHG simulations in a stochastic model using the following assumptions: (1) The climate change scenario was determined using the pattern scaling technique, i.e. it was defined as a product of the standardised scenario and $\Delta T_{\mathrm{G}}$. (2) The intra-GCM uncertainty was not considered, as it was already included in the interGCM uncertainty, which was derived from a set of scenarios based on single runs of individual GCMs. (3) Uncertainty due to the choice of site (as discussed above) was not considered, because it was related to the variability of the scenarios over a territory of a given size, while here we are concerned with the uncertainty related to a specific site. (4) The above assumptions imply that the uncertainty in the standardised scenario is given by the inter-GCM uncertainty and the regression-based uncertainty; for simplicity, we assumed that these 2 uncertainties (deviations from the mean) are normally distributed. (5) Uncertainties in $\Delta T_{\mathrm{G}}$ were not considered separately; we used the probability distribution function developed by Wigley et al. (2001), who found on the basis of a perturbation analysis of a simple climate model that $T_{\mathrm{G}}$ will rise by 1.7 to $4.9^{\circ} \mathrm{C}(90 \%$ probability interval) from 1990 to 2100 . We approximated the probability distribution function in Wigley et al. (2001) by the lognormal distribution: $\left(\Delta T_{\mathrm{G}}+4.3\right) \sim \log \mathrm{N}(2,0.13)$ for 2100 .

On the assumption that the 3 types of uncertainty act independently, the resulting stochastic model is

$$
X=\left(X_{0}+e_{\mathrm{GCM}}+e_{\text {reg }}\right) \times(Y-4.3)
$$

where $X$ is a projected change in the variable, $X_{0}$ is the mean value of the standardised change in the variable, $e_{\mathrm{GCM}}$ and $e_{\mathrm{reg}}$ are random numbers with $\mathrm{N}\left(0, s_{\mathrm{GCM}}^{2}\right)$ and $\mathrm{N}\left(0, s_{\text {reg }}^{2}\right)$ distributions, $s_{\mathrm{GCM}}^{2}$ and $s_{\text {reg }}^{2}$ are variances representing inter-GCM and regression uncertainties, and $Y$ is a random number with a $\log N(2,0.13)$ distribution. A single realisation of $X$ is then driven by 3 random values: $e_{\mathrm{GCM}}, e_{\text {reg }}$ and $Y$. In cases where the uncertainty due to $\Delta T_{\mathrm{G}}$ is omitted, the term $(Y-4.3)$ in Eq. (2) is replaced by its median value, 3.09. When the inter-GCM and/or regression uncertainties are omitted, the values of $e_{\mathrm{GCM}}$ and/or $e_{\text {reg }}$ are set to zero.

This stochastic model was used to assess uncertainty in temperature and precipitation changes projected for 2100. For each month and each of the 2 variables, Eq. (2) was used to generate 50000 realisations of $X$ to produce a smooth probability distribution function (PDF). Fig. 9 shows the combined effect of the 3 uncertainties (inter-GCM uncertainty, uncertainty related to 

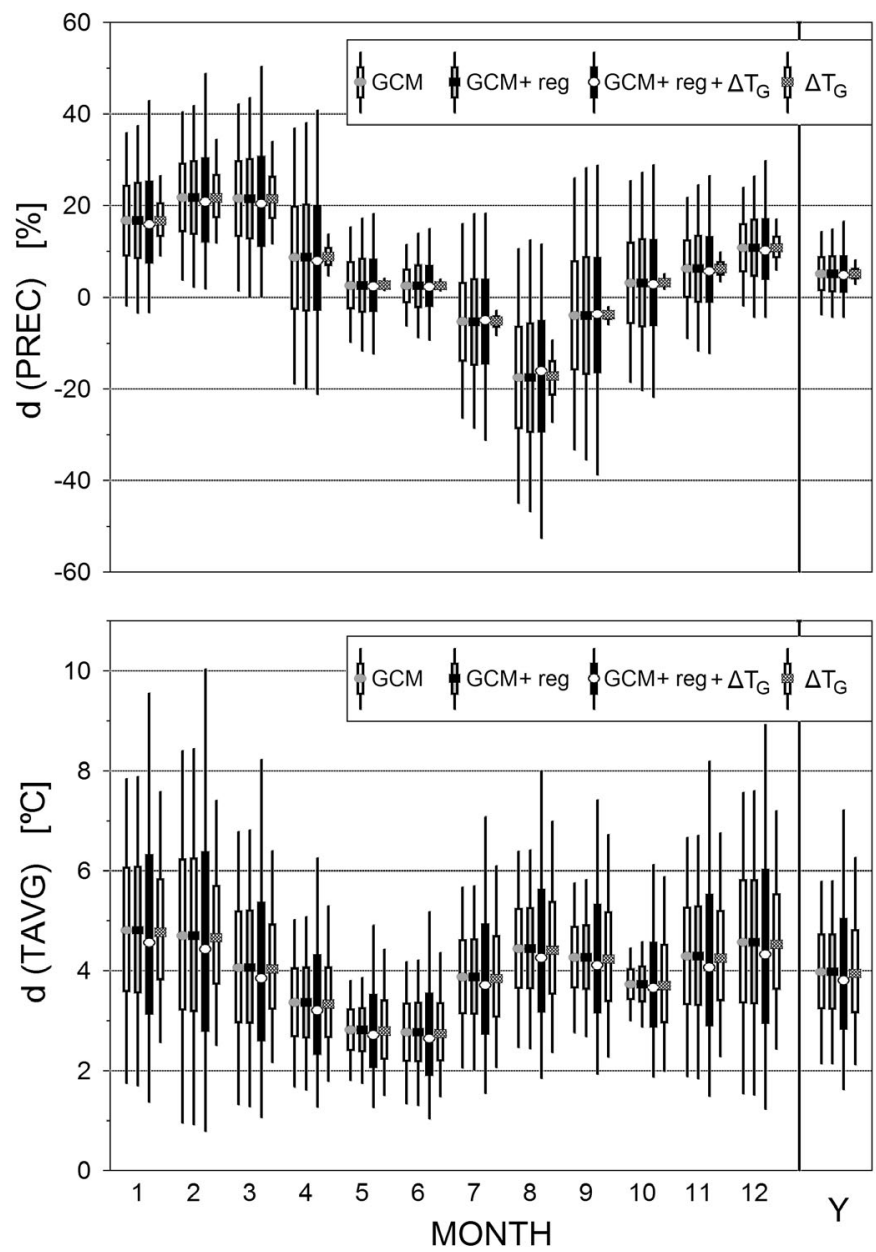

Fig. 9. Combination of uncertainties in changes in precipitation (top) and temperature (bottom) projected for the Czech Republic in 2100 using the pattern scaling technique. Vertical bars represent percentiles $(5 \%, 25 \%, 50 \%, 75 \%, 95 \%)$ of the distribution function of projected changes (see Section 4.3.5. for description of the stochastic model). GCM: changes affected only by inter-GCM uncertainty; GCM+reg: combined effect of uncertainties due to choice of GCM and linear regression used to determine the standardised scenarios; GCM+reg $+\Delta T_{\mathrm{G}}$ : effect of the previous 2 uncertainties combined with uncertainty in the change of the global mean temperature; $\Delta T_{\mathrm{G}}$ : uncertainty only due to $\Delta T_{\mathrm{G}}$

the regression technique and uncertainty in $\Delta T_{\mathrm{G}}$ ) in terms of the quantiles of the PDFs for individual months. The effects of the 3 uncertainties, both singly and in combination, on the PDF are illustrated in Fig. 10 for the change in January precipitation. In Fig. 9 we see:

(1) Uncertainty due to the regression contributes only insignificantly to the overall uncertainty in both temperature and precipitation projections. This relates to the fact that the regression uncertainty is lower compared to the inter-GCM uncertainty (Fig. 5), and the aggregate uncertainty (expressed in terms of standard deviation) results as the root square of the sum of squares of the 2 uncertainties-e.g. when the latter uncertainty is $50 \%$ lower than the former uncertainty alone, then the aggregate uncertainty is only $12 \%$ higher.

(2) For temperature, the effect of $\Delta T_{\mathrm{G}}$ uncertainty alone on monthly temperature changes is $14 \%$ higher (increase in the interquartile range, averaged over $12 \mathrm{mo}$ ) than that of inter-GCM uncertainty alone, and $9 \%$ higher than the aggregate inter-GCM plus regression uncertainty. Consequently the added $\Delta T_{\mathrm{G}}$ uncertainty significantly increases the aggregate uncertainty: the combined effect of all 3 uncertainties is $55 \%$ higher (considering the interquartile range) than interGCM uncertainty alone, and $60 \%$ higher if the $90 \%$ uncertainty interval is considered.

(3) For precipitation, the effect of $\Delta T_{\mathrm{G}}$ uncertainty alone is much lower than that of inter-GCM uncertainty, because the final scenario is obtained as a product of $\Delta T_{\mathrm{G}}$ and the standardised scenario, which is relatively close to zero (compared to the standardised temperature scenario). Consequently the combined effect of all 3 uncertainties is only $14 \%$ higher than that of inter-GCM uncertainty alone $(22 \%$ in the case of the $90 \%$ uncertainty interval).

Uncertainty in the climate change scenario thus increases with increasing number of uncertainties. However, in some cases, the combined effect of all uncertainties is not significantly higher than the effect of the most significant uncertainty alone, e.g. in the

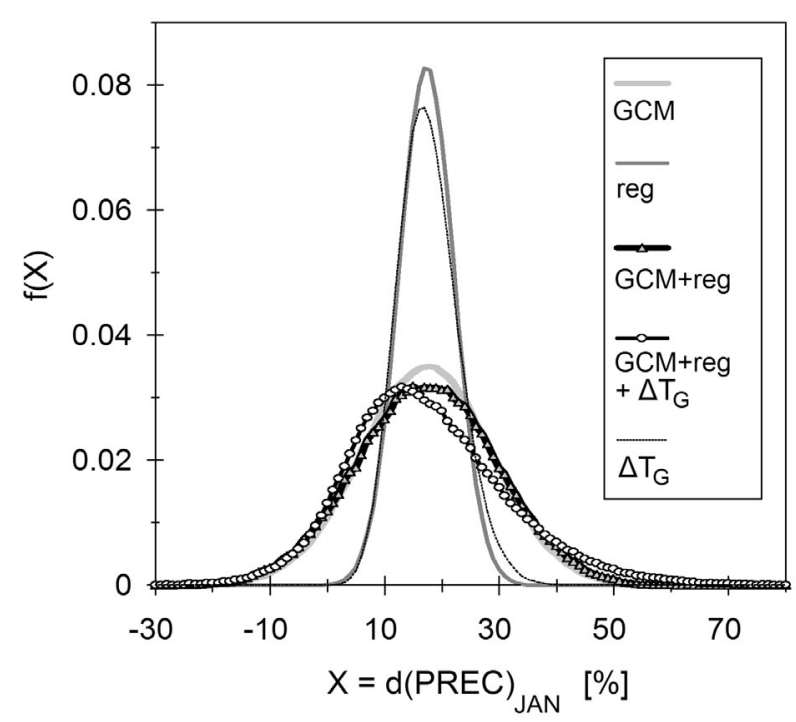

Fig. 10. Probability distribution function (PDF) of January precipitation change modelled by Eq. (2). GCM, reg, $\Delta T_{\mathrm{G}}$ PDFs driven only by inter-GCM uncertainty, linear regression uncertainty, or uncertainty due to $\Delta T_{\mathrm{G}}$, respectively. GCM+reg, GCM+reg+ $\Delta T_{\mathrm{G}}$ PDFs driven by combinations of the uncertainties specified 
precipitation scenario dominated by inter-GCM uncertainty.

\subsection{Choice of a representative set of climate change scenarios}

Based on the results of the validation tests (Section 3) and the uncertainty analysis (Section 4.3), we recommend a combination of 3 GCM-based standardised scenarios and 3 projections of $T_{\mathrm{G}}$ for impact studies in the Czech Republic. The GCMs selected represent various combinations of the changes in temperature and precipitation, and the 3 values of $\Delta T_{\mathrm{G}}$ represent low, intermediate and high estimates of the magnitude of change. This recommendation represents a tradeoff between using only a single scenario (not recommended as it does not address any of the uncertainties) and all scenarios (desirable but too laborious for many impact studies).

\subsubsection{Choice of GCM}

It is preferable to use climate change scenarios based on those GCMs which simulate the present climate reasonably well (based on the assumption that this will hold true for the future climate). The results obtained in the validation analysis (Table 3 ) suggest that CSIRO (or NCAR), ECHAM and HadCM are a representative triplet; the ECHAM-based scenarios are already commonly used in the Czech Republic. In this set of scenarios, HadCM would represent climate change characterised by lower temperature increase (especially in spring) and insignificant change in annual precipitation (decrease in summer and increase in winter and spring). ECHAM would represent climate change with a higher temperature increase and slight precipitation decrease (due decreases in April and summer precipitation). CSIRO or NCAR would represent climate change with lower temperature increase and moderate precipitation increase. Although the averaging of scenarios obtained from various GCMs is not generally recommended, we think that a scenario averaged over several GCMs might be acceptable when a single scenario is required by impact researchers. The physical inconsistency of an averaged scenario appears to be less when the changes defined by individual scenarios are relatively small. Trnka et al. (2004) found that the impact on crop yields predicted by an averaged climate change scenario fitted the impact averaged over results from single GCM scenarios. An averaged scenario is also used in SCENGEN (Hulme et al. 1995, 2000), a scenario generator widely used in impact studies.
4.4.2. Choice of parameters for estimating change in global mean temperature

Three values of $\Delta T_{\mathrm{G}}$ can be used to scale the standardised scenarios: low, intermediate and high estimates. A similar approach was adopted by Hulme et al. (2002). The most straightforward way is to base the estimates on the following combinations of the emission scenario and climate sensitivity factor: low estimate of $\Delta T_{\mathrm{G}}$ based on low emission scenario (IS92c or SRES-B1) and low climate sensitivity $\left(1.5^{\circ} \mathrm{C}\right)$; intermediate estimate of $\Delta T_{\mathrm{G}}$ based on intermediate emission scenario (IS92a or SRES-A1) and intermediate climate sensitivity $\left(2.5^{\circ} \mathrm{C}\right)$; high estimate of $\Delta T_{\mathrm{G}}$ based on high emission scenario (IS92e or SRES-A2) and high climate sensitivity $\left(4.5^{\circ} \mathrm{C}\right)$. In any case, however, one should be very careful in using high values of the scaling factor as they could result in unrealistic annual cycles of some climatic variables. For example, by multiplying the CCSR-based standardised scenario with $\Delta T_{\mathrm{G}}=5^{\circ} \mathrm{C}$, precipitation would decrease by $60 \%$ in August and increase by $65 \%$ in March-such a distortion of the annual cycle does not appear realistic. To avoid this situation, one should not employ a scaling factor that is close to or greater than the maximum value of GCM-simulated $\Delta T_{\mathrm{G}}$ involved in determining the standardised scenarios from a given GCM. This constraint is consistent with the non-transferability of the patterns to emission scenarios with higher radiative forcing (see Section 4.2). The values of $\Delta T_{\mathrm{G}}$ related to the 2070 to 2099 period (Table 2) may be used to approximate these upper limits for this study.

\section{SUMMARY AND CONCLUSIONS}

The pattern scaling technique was applied to climate change scenarios for the territory of the Czech Republic from the output of several GCMs for 4 variables: daily mean temperature, daily temperature range, precipitation amount and solar radiation sum. The GCMs were validated in terms of annual cycles derived from the $30 \mathrm{yr}$ (1961-1990) slice of GCM integrations compared to averaged observations at 5 South Moravian stations, and $0.5 \times 0.5^{\circ}$ gridded observational data available from CRU. The annual cycles were compared (Table 3) using several quantitative measures.

The standardised climate change scenarios (Fig. 4) were developed from 90 yr (2010-2099) data simulated by $7 \mathrm{GCMs}$. Values of $\Delta T_{\mathrm{G}}$ which are used to scale the standardised scenario, were calculated by the simple climate model MAGICC for 3 selected periods and 2 fixed $\mathrm{CO}_{2}$ concentrations, 3 climate sensitivities and 5 emission scenarios (Table 5). 
Sources of uncertainty were divided into 2 groups. (1) Uncertainties in determining the standardised scenario: regression technique, choice of GCM, internal GCM variability, and choice of site. Only these uncertainties affect the seasonal cycle of climate change; the greatest uncertainty is related to the choice of GCM, but internal GCM uncertainty is similar to inter-GCM uncertainty in some cases (e.g. in autumn months for the daily temperature range; see Fig. 5). The magnitude of the uncertainty due to the regression technique is higher than the choice-of-site uncertainty, but lower than the inter-GCM uncertainty. The pattern scaling technique assumes proportionality of the changes in climatic characteristics to $\Delta T_{\mathrm{G}}$. This assumption is met only for changes in temperature in the Czech territory. In light of the great uncertainty in the monthly changes of some variables, it might be preferable to present the scenario in terms of the seasonal changes or to smooth the monthly changes, and thereby reduce month-to-month variability.

(2) Uncertainties in determining $\Delta T_{\mathrm{G}}$ : choice of emission scenario and the value for climate sensitivity. The differences between the emission scenarios are lower than the uncertainty related to the climate sensitivity in the first half of the 21st century, but higher in the case of the IS92 scenarios at the end of the century. The range of $\Delta T_{\mathrm{G}}$ values related to the 4 SRES scenarios is lower and the uncertainty due to the climate sensitivity dominates at the end of the century.

Aerosols generally have a cooling effect on the surface air temperature. Averaged over all GCMs, the effect of aerosols on standardised temperature change in the Czech Republic is slightly negative (positive in summer, negative in the rest of the year) and the effect on precipitation change is indistinct in the first half of the year and positive in the second half of the year. Differences between the GHG and GHG+A scenarios are mostly statistically significant. The mean magnitude of the aerosol effect is mostly lower than its inter-GCM variability, which is lower than (in the case of the temperature changes) or similar to (in the case of precipitation) the inter-GCM uncertainty in the GHG simulations. Sensitivity to the uncertainty in sulphate forcing was significantly lower in the SRES scenarios than in the IS92a scenario (Houghton et al. 2001).

A stochastic model was developed to assess the combined effect of inter-GCM uncertainty, regression uncertainty and uncertainty in $\Delta T_{\mathrm{G}}$ on temperature and precipitation scenarios. The combined effect of the first 2 uncertainties was not significantly higher than the effect of inter-GCM uncertainty alone. While uncertainty in the temperature scenario is dominated by inter-GCM and $\Delta T_{\mathrm{G}}$ uncertainty, uncertainty in the precipitation scenario is dominated only by inter-GCM uncertainty. For temperature, the combined effect of all 3 uncertainties (average value of the interquartile range for $12 \mathrm{mo}$ ) is $55 \%$ higher than inter-GCM uncertainty alone. For precipitation, the combined uncertainty is only $14 \%$ higher.

A set of scenarios is recommended for use in impact studies in the Czech Republic. The set consists of combining 3 GCMs (CSIRO or NCAR, ECHAM, HadCM) and 3 values (low, intermediate, high) of the scaling factor. More recent GCM simulations and emission scenarios, and outputs from regional climate models are being made available for developing climate change scenarios. However, we think that some of the results presented here are applicable: (1) assessment of the regression uncertainty in determining the standardised scenario from a long GCM simulation and (2) the stochastic model for the combination of the uncertainties. We plan to use new GCM simulations to extend this analysis to the planet as a whole.

Acknowledgements. This study was sponsored by the Grant Agency of the Czech Republic (Project 521/02/0827) and the research programme of the Ministry of Environment of the Czech Republic (Project VaV/640/18/03-CzechCarbo). The observational daily weather series were provided by the Czech Hydrometeorological Institute, the outputs from GCMs were obtained from the IPCC-DDC web page, gridded observational data and the MAGICC climate model were obtained from the Climatic Research Unit (CRU). We greatly acknowledge the policy of IPCC and CRU, who provide free access to their products.

\section{LITERATURE CITED}

Alexandrov VA, Hoogenboom G (2000) Vulnerability and adaptation assessments of agricultural crops under climate change in the southeastern USA. Theor Appl Climatol 67:45-63

Andronova N, Schlesinger ME (2001) Objective estimation of the probability distribution for climate sensitivity. J Geophys Res 106(D19):22605-22612

Buchtele J, Buchtelova M, Fortova M, Dubrovsky M. (1999) Runoff changes in Czech river basins - the outputs of rainfall-runoff simulations using different climate change scenarios. J Hydrol Hydromech 47:180-194

Covey C, AchutaRao KM, Cubasch U, Jones P, Lambert SJ, Mann ME, Phillips TJ, Taylor KE (2003) An overview of results from the Coupled Model Intercomparison Project. Global Planet Change 37:103-133

Dubrovsky M, Zalud Z, Stastna M (2000) Sensitivity of CERES-maize yields to statistical structure of daily weather series. Clim Change 46:447-472

Gates WL, Henderson-Sellers A, Boer GJ, Folland CK and 6 others (1996) Climate models-evaluation. In: Houghton JT, Meira Filho LG, Callander BA, Harris N, Kattenberg A, Maskell K (eds) Climate change 1995: the science of climate change. Contribution of Working Group I to the Second Assessment Report of the Intergovernmental Panel on Climate Change. Cambridge University Press, Cambridge, p 228-284

Giorgi F, Francisco R (2000) Evaluating uncertainties in the prediction of regional climate change. Geophys Res Lett 
27:1295-1298

Giorgi F, Bi X, Pal J (2004) Mean, interannual variability and trends in a regional climate change experiment over Europe. II: Climate change scenarios (2071-2100). Clim Dyn 23:839-858

Goldammer JG, Price C (1998) Potential impacts of climate change on fire regimes in the tropics based on MAGICC and a GISS GCM-derived lightning model. Clim Change 39:273-296

Gregory JM, Stouffer RJ, Raper SCB, Stott PA, Rayner NA (2002) An observationally based estimate of the climate sensitivity. J Clim 15:3117-3121

Harvey LDD, Gregory J, Hoffert M, Jain A and 5 others (1997) An introduction to simple climate models used in the IPCC Second Assessment Report. IPCC Tech Paper 2, Intergovernmental Panel on Climate Change, Geneva

Hejzlar J, Dubrovsky M, Buchtele J, Ruzicka M (2003) The effect of climate change on the concentration of dissolved organic matter in a temperate stream (the Malse River, South Bohemia). Sci Total Environ 310:143-152

Houghton JT, Meira Filho LG, Callander BA, Harris N, Kattenberg A, Maskell K (eds) (1996) Climate change 1995: the science of climate change. Contribution of Working Group I to the Second Assessment Report of the Intergovernmental Panel on Climate Change. Cambridge University Press, Cambridge

Houghton JT, Ding Y, Griggs DJ, Noguer M, van der Linden PJ, Xiaosu D (eds) (2001) Climate change 2001: the scientific basis. Contribution of Working Group I to the Third Assessment Report of the Intergovernmental Panel on Climate Change (IPCC). Cambridge University Press, Cambridge

Huntingford C, Cox PM (2000) An analogue model to derive additional climate change scenarios from existing GCM simulations. Clim Dyn 16:575-586

Hulme M, Jiang T, Wigley TML (1995) SCENGEN: a climate change SCENario GENerator, Software User Manual, Version 1.0. Climatic Research Unit, University of East Anglia, Norwich

Hulme M, Wigley TML, Barrow EM, Raper SCB, Centella A, Smith S, Chipanshi AC (2000) Using a climate scenario generator for vulnerability and adaptation assessments: MAGICC and SCENGEN Version 2.4 Workbook. Climatic Research Unit, Norwich

Hulme M, Jenkins GJ, Lu X, Turnpenny JR and 12 others (2002) Climate change scenarios for the United Kingdom: the UKCIP02 Scientific Report. Tyndall Centre for Climate Change Research, University of East Anglia, Norwich

Huth R (1997) Continental-scale circulation in the UKHI GCM. J Clim 10:1545-1561

Huth R, Kysely J, Pokorna L (2000) A GCM simulation of heat waves, dry spells, and their relationships to circulation. Clim Change 46:29-60

Janous D, Hadas P, Dubrovsky M (2003) Dopady klimaticke zmeny v Moravskoslezskych Beskydech (impacts of climate change on forests in the Moravskoslezske Beskydy Mountains). Lesnicka prace 82(2):24-25

Kalvova J, Nemesova I (1998) Estimating autocorrelations of daily extreme temperatures in observed and simulated climates. Theor Appl Climatol 59:151-164

Knutti R, Stocker TF, Joos F, Plattner GK (2002) Constraints on radiative forcing and future climate change from observations and climate model ensembles. Nature 416:719-723.

Kont A, Jaagus J, Aunap R (2003) Climate change scenarios and the effect of sea-level rise for Estonia. Global Planet Change 36:1-15

Maytín CE, Acevedo MF, Jaimez R, Andressen R, Harwell
MA, Robock A, Azkcar A (1995) Potential effects of global climatic change on the phenology and yield of maize in Venezuela. Clim Change 29:189-211

McCarthy JJ, Canziani OF, Leary NA, Dokken DJ, White KS (eds) (2001) Climate change 2001: impacts, adaptation \& vulnerability. Contribution of Working Group II to the Third Assessment Report of the Intergovernmental Panel on Climate Change (IPCC). Cambridge University Press, Cambridge

McKendry IG, Steyn DG, McBean G (1995) Validation of synoptic circulation patterns simulated by the Canadian Climate Centre General Circulation Model for Western North America. Atmosphere-Ocean 33:809-825

Mearns LO, Rosenzweig C, Goldberg R (1992) Effect of changes in interannual climatic variability on CERESwheat yields: sensitivity and $2 \times \mathrm{CO}_{2}$ general circulation model studies. Agric For Meteorol 62:159-189

Mearns LO, Rosenzweig C, Goldberg R (1997) Mean and variance change in climate scenarios: methods, agricultural applications, and measures of uncertainty. Clim Change 35:367-396

Metz B, Davidson O, Swart R, Pan J (Eds.) (2001) Climate change 2001: mitigation. Contribution of Working Group III to the Third Assessment Report of the Intergovernmental Panel on Climate Change. Cambridge University Press, Cambridge

Mitchell JFB, Manabe S, Meleshko V, Tokioka T (1990) Equilibrium climate change and its implications for the future. In: Houghton JT, Jenkins GJ, Ephraums JJ (eds) Climate change: the IPCC scientific assessment. report prepared by Working Group I. Cambridge University Press, Cambridge, p 131-164

Mitchell JFB, Johns TC, Eagles M, Ingram WJ, Davis RA (1999) Towards the construction of climate change scenarios. Clim Change 41:547-581

Mitchell TD (2003) Pattern scaling. An examination of the accuracy of the technique for describing future climates. Clim Change 60:217-242

Nakicenovic N, Swart R (eds) (2000) Emissions scenarios. Special report of the Intergovernmental Panel on Climate Change. Cambridge University Press, Cambridge

Nemesova I, Kalvova J (1997) On the validity of ECHAM-simulated daily extreme temperatures. Studia Geoph Geod 41:396-406

Nemesova I, Kalvova J, Dubrovsky M (1999) Climate change projections based on GCM-simulated daily data. Studia Geoph Geod 43:201-222

New M, Hulme M, Jones PD (1999) Representing twentieth century space-time climate variability. Part 1: development of a 1961-90 mean monthly terrestrial climatology. J Clim 12:829-856

Randall DA (ed) 2000: General circulation model development. Academic Press, San Diego

Raper SCB, Warrick RA, Wigley TML (1996) Global sea level rise: past and future. In: Milliman JD, Haq BU (eds) Sealevel rise and coastal subsidence: causes, consequences and strategies, Kluwer, Dordrecht, p.11-45

Riha SJ, Wilks DS, Simoens P (1996) Impact of temperature and precipitation variability on crop model predictions. Clim Change 32:293-311

Santer BD, Wigley TML, Schlesinger ME, Mitchell JFB (1990) Developing climate scenarios from equilibrium GCM results. Report No.47, Max Planck Institute für Meteorologie, Hamburg

Semenov MA, Porter JR (1995) Climatic variability and the modelling of crop yields. Agric For Meteorol 73:265-283

Semenov MA, Barrow EM (1997) Use of a stochastic weather 
generator in the development of climate change scenarios. Clim Change 35:397-414

Trnka M, Dubrovsky M, Zalud Z (2004) Climate change impacts and adaptation strategies in spring barley production in the Czech Republic. Clim Change 64:227-255

Wigley TML, Raper SCB (1987) Thermal expansion of sea water associated with global warming Nature 330: $127-131$

Wigley TML, Raper SCB (1992) Implications of revised IPCC emissions scenarios. Nature 357:293-300

Editorial responsibility: Claire Goodess,

Norwich, UK
Wigley TML, Raper SCB (1993) Future changes in globalmean temperature and sea level. In: Warrick RA, Barrow E, Wigley TML (eds) Climate and sea level change: observations, projections and implications, Cambridge University Press, Cambridge, p 111-133

Wigley TML, Raper SCB (2001) Interpretation of high projections for global-mean warming. Science 293:451-454

Zalud Z, Dubrovsky M (2002) Modelling climate change impacts on maize growth and development in the Czech Republic. Theor Appl Climatol 72:85-102

Submitted: May 21, 2003; Accepted: May 25, 2005

Proofs received from author(s): July 14, 2005 